
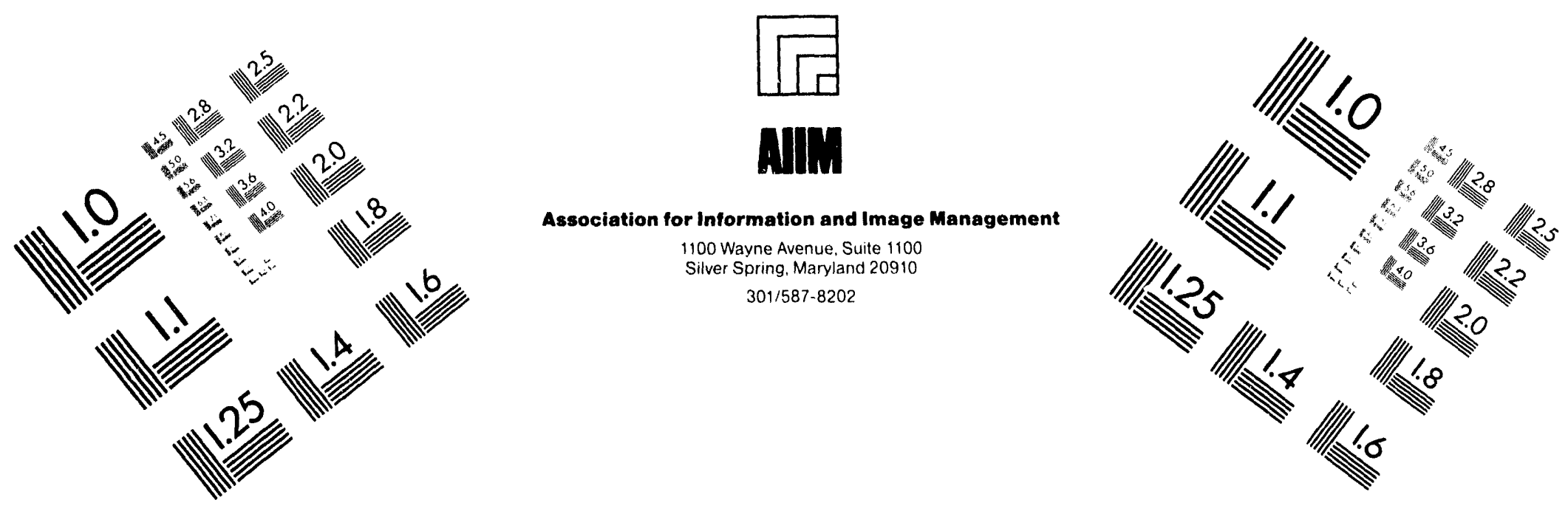

\title{
Centimeter
}

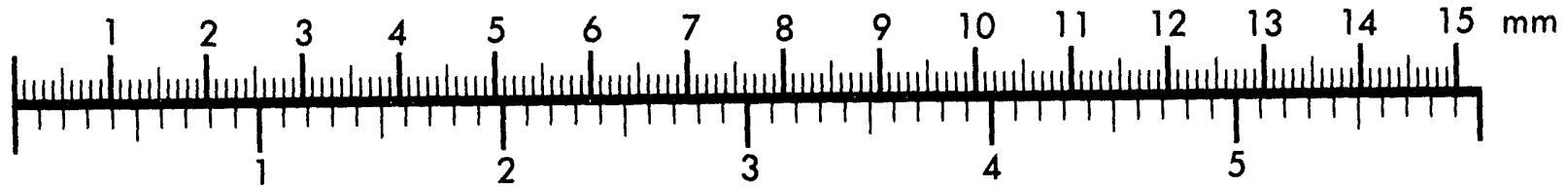

Inches
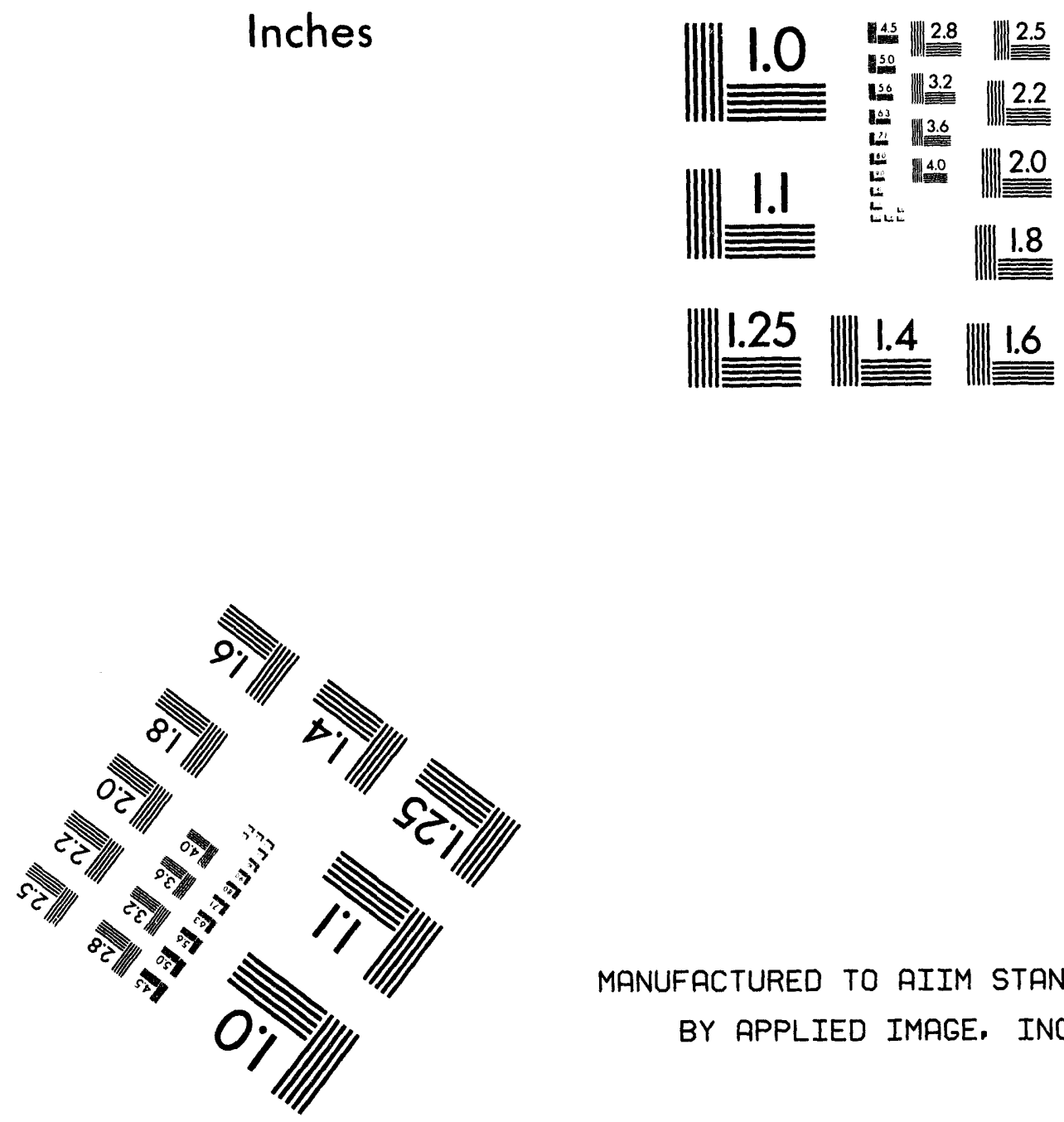

MANUFACTURED TO AIIM STANDARDS

BY APPLIED IMAGE. INC.

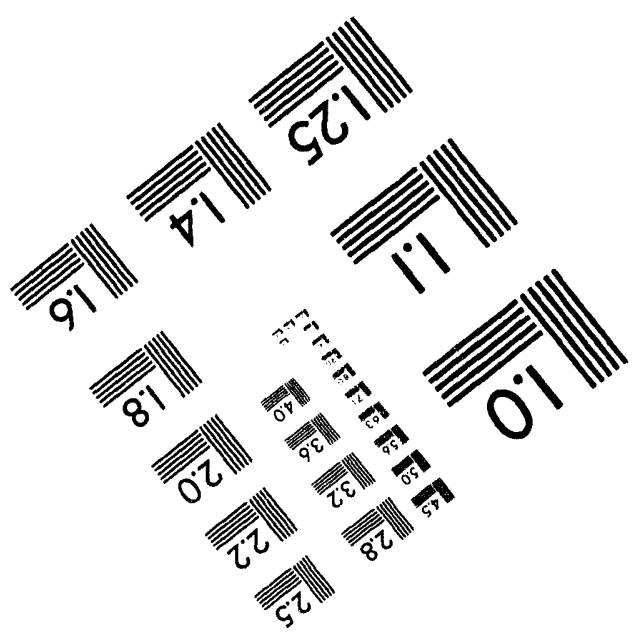



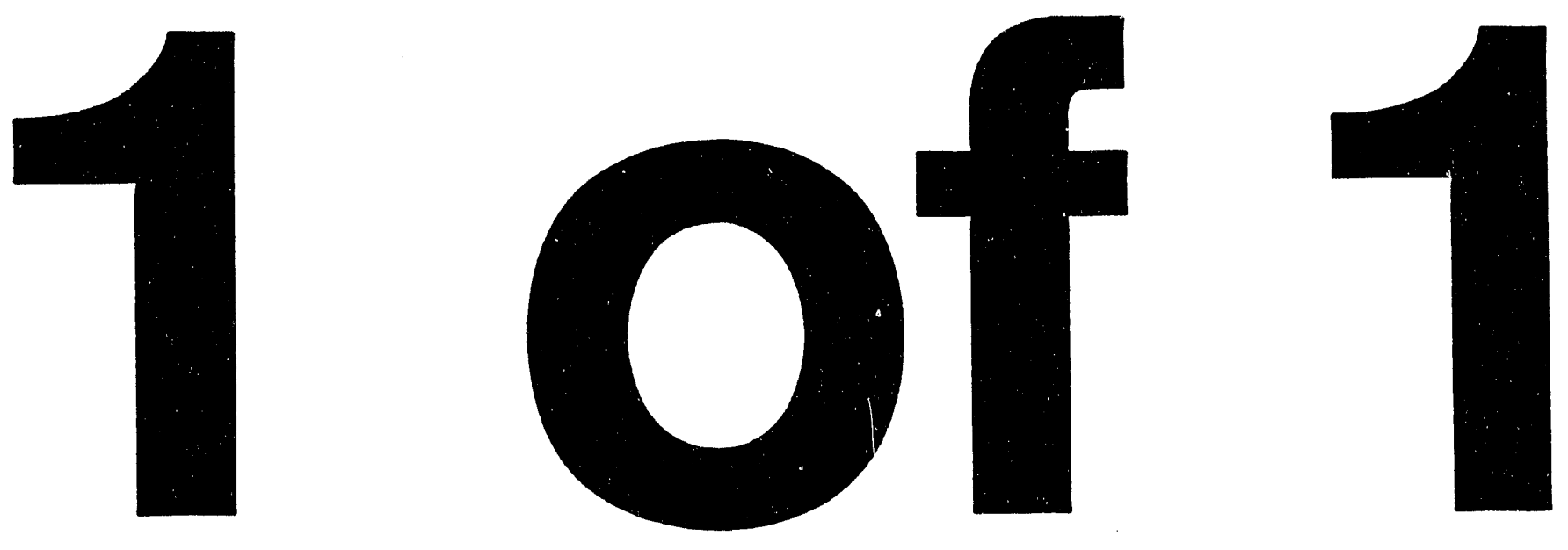
NUREG/CR-5344

ANL/EES-TM-364

Rev. 1

\section{Replacement Energy \\ Cost Analysis Package \\ (RECAP): User's Guide}

Manuscript Completed: March 1994

Date Published: July 1994

Prepared by J. C. VanKuiken, D. L. Willing

Argonne National Laboratory

9700 South Cass Avenue

Argonne, IL 60439

Prepared for

Division of Regulatory Applications

Office of Nuclear Regulatory Research

U.S. Nuclear Regulatory Commission

Washington, DC 20555-0001

NRC FIN A2199 


\begin{abstract}
A microcomputer program called the Replacement Energy Cost Analysis Package (RECAP) has been developed to assist the U.S. Nuclear Regulatory Commission (NRC) in determining the replacement energy costs associated with short-tern shutdowns or deratings of one or more nuclear reactors. The calculations are based on the seasonal, unit-specific cost estimates for 1993-1996 previously published in NRC Report NUREG/CR-4012, Vol. 3 (1992), for all 112 U.S. reactors. Because the RECAP program is menu-driven, the user can define specific case studies in terms of such parameters as the units to be included, the length and timing of the shutdown or derating period, the unit capacity factors, and the reference year for reporting cost results. In addition to simultaneous shutdown cases, more complicated situations, such as overlapping shutdown periods or shutdowns that occur in different years, can be examined through the use of a present-worth calculation option.
\end{abstract}




\section{CONTENTS}

ABSTRACT $\ldots \ldots \ldots \ldots \ldots \ldots \ldots \ldots \ldots \ldots \ldots \ldots \ldots \ldots \ldots \ldots \ldots$

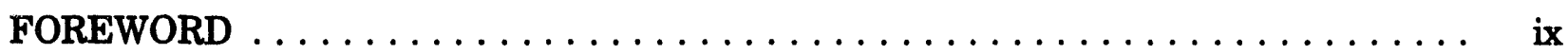

ACKNOWLEDGMENTS $\ldots \ldots \ldots \ldots \ldots \ldots \ldots \ldots \ldots \ldots \ldots$

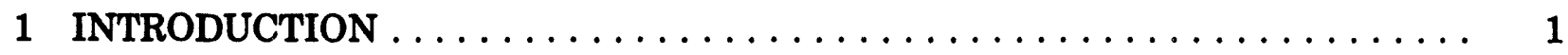

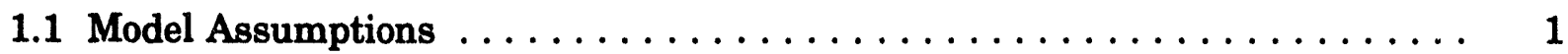

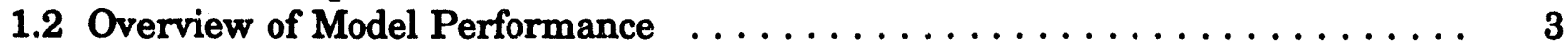

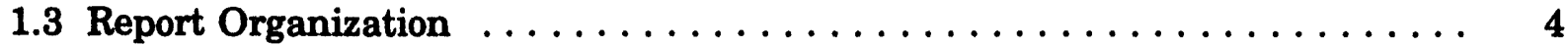

2 MICROCOMPUTER INSTALLATION PROCEDURES $\ldots \ldots \ldots \ldots \ldots \ldots$

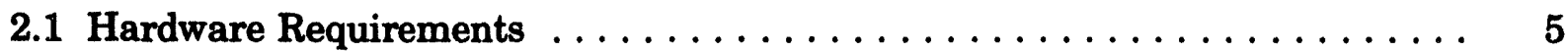

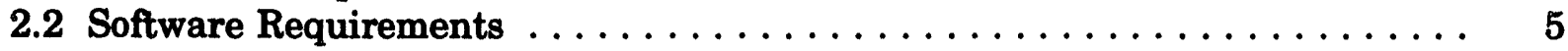

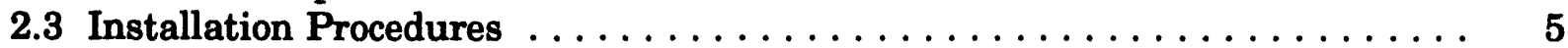

3 OPERATING PROCEDURES $\ldots \ldots \ldots \ldots \ldots \ldots \ldots \ldots \ldots \ldots$

3.1 Function Keys and Screen Format $\ldots \ldots \ldots \ldots \ldots \ldots \ldots$

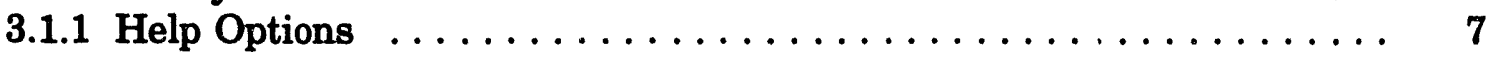

3.1.2 Use of the ENTER, F10, and ESCAPE Keys . . . . . . . . . . . 7

3.1.3 Screen-Dependent Function Keys $\ldots \ldots \ldots \ldots \ldots \ldots \ldots \ldots \ldots$

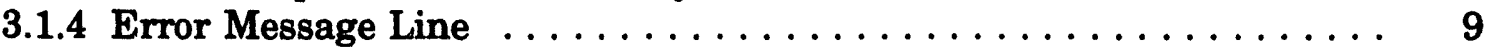

3.1.5 Screen Reference Numbers . . . . . . . . . . . . . . . . 9

3.2 Overview and Flowcharts of the Frogram Options in the Main Menu . . . . . 9

3.3 Option 1: Reviewing the RECAP Abstract and Assumptions . . . . . . . 11

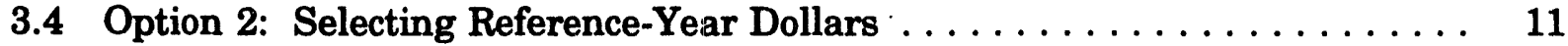

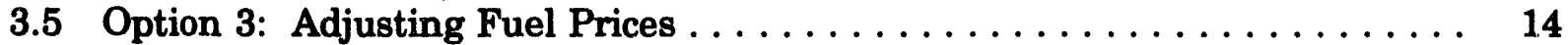

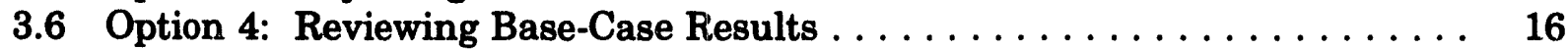

3.7 Option 5: Selecting Units for Analysis $\ldots \ldots \ldots \ldots \ldots \ldots \ldots$

3.7.1 Screen-Specific Help Messages . . . . . . . . . . . . . . . . . 17

3.7.2 Reactor-Specific Reference Data . . . . . . . . . . . . . 17

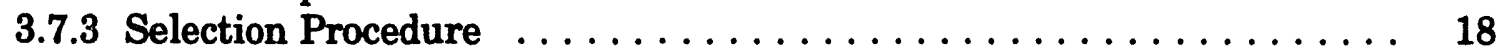

3.8 Option 6: Performing an Energy Replacement Cost Analysis . . . . . . . 25

3.8.1 Specifying the Shutdown or Derating Period . . . . . . . . . . 25

3.8.2 Selecting General Conditions for the Analysis . . . . . . . . . . . 25

3.8.3 Choosing between Shutdown and Derating Alternatives . . . . . . 29

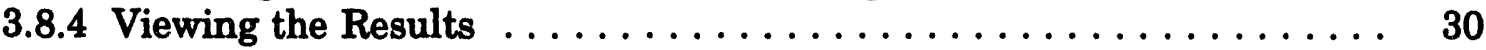

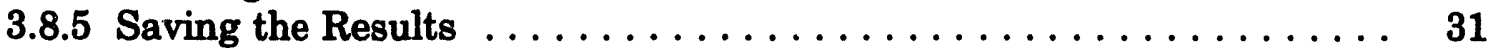

3.8.6 Continuing with Additional Cost Analyses $\ldots \ldots \ldots \ldots \ldots \ldots$

3.9 Option 7: Performing a Present-Worth Analysis $\ldots \ldots \ldots \ldots \ldots \ldots$

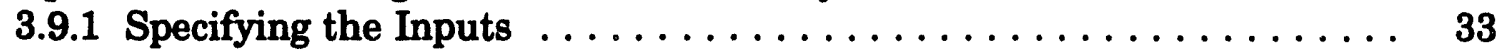

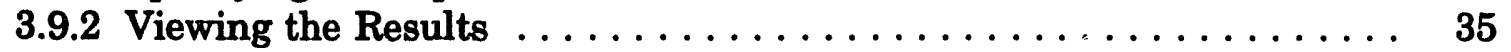

3.9.3 Continuing with Additional Present-Worth Analyses $\ldots \ldots \ldots \ldots \ldots$

3.10 Deleting Files $\ldots \ldots \ldots \ldots \ldots \ldots \ldots \ldots \ldots \ldots \ldots \ldots \ldots \ldots$ 


\section{CONTENTS (Cont.)}

3.11 Analysis Strategies for Overlapping Shutdowns $\ldots \ldots \ldots \ldots \ldots \ldots$

3.12 Exiting RECAP $\ldots \ldots \ldots \ldots \ldots \ldots \ldots \ldots \ldots \ldots \ldots \ldots \ldots$

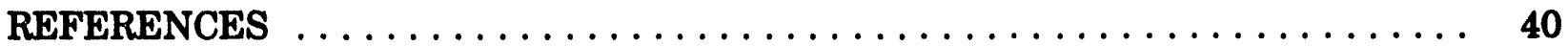

APPENDIX: Diagram of Screens by Operational Sequence $\ldots \ldots \ldots \ldots \ldots \ldots$

\section{FIGURES}

1 Screen R005: Introductory Message $\ldots \ldots \ldots \ldots \ldots \ldots \ldots \ldots$

2 Sample Screen Layout Showing Screen-Dependent Function Keys . . . . . . . . 8

3 Screen R010: Main RECAP Menu $\ldots \ldots \ldots \ldots \ldots \ldots \ldots \ldots \ldots$

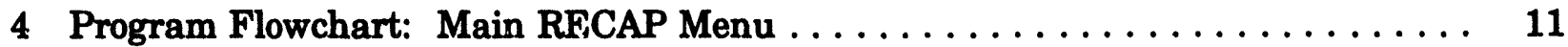

5 Program Flowchart: Unit Selection Criteria $\ldots \ldots \ldots \ldots \ldots \ldots \ldots$

6 Program Flowchart: Replacement Energy Cost Analysis . . . . . . . . . . . 13

7 Program Flowchart: Present-Worth Analysis . . . . . . . . . . . . . . . 14

8 Screen R015: Select Reference Year for Reporting Cost Results . . . . . . . . . . 15

9 Screen R030: Make Fuel Price Adjustments $\ldots \ldots \ldots \ldots \ldots \ldots$

10 Screen R020: Select Units for Analysis $\ldots \ldots \ldots \ldots \ldots \ldots \ldots$

11 Screen R026: Brief Display of Currently Selected Units $\ldots \ldots \ldots \ldots$

12 Screen R027: Detailed Review of Currently Selected Units . . . . . . . . . . 19

13 Screen R048: Select Units by Name . . . . . . . . . . . . . . . . . 19

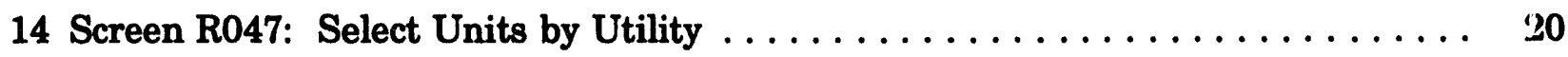

15 Screen R046: Select Units by Reactor Type . . . . . . . . . . . . . . 20

16 Screen R045: Select Units by Power Pool $\ldots \ldots \ldots \ldots \ldots \ldots \ldots$

17 Screen R049: Select Units by NERC Region $\ldots \ldots \ldots \ldots \ldots \ldots \ldots$

18 Screen R050: Select Units by Reactor Supplier . . . . . . . . . . . . . 22 


\section{FIGURES (Cont.)}

19 Screen R051: Select Units by Turbine Supplier $\ldots \ldots \ldots \ldots \ldots \ldots \ldots \ldots 22$

20 Screen R052: Select Units by Architect Engineer .............. 23

21 Screen R053: Select Units by Constructor $\ldots \ldots \ldots \ldots \ldots \ldots \ldots \ldots \ldots$

22 Screen R060: Specify Shutdown Schedule for All Selected. Units $\ldots \ldots \ldots \ldots 26$

23 Screen R055: Select General Conditions for Cost Analysis . . . . . . . . . 26

24 Screen R110: Select Units for Changes in Start-up Dates $\ldots \ldots \ldots \ldots \ldots 27$

25 Screen R115: Change Start-up Dates $\ldots \ldots \ldots \ldots \ldots \ldots \ldots \ldots \ldots \ldots \ldots \ldots \ldots \ldots$

26 Screen R120: Select New Capacity Factor $\ldots \ldots \ldots \ldots \ldots \ldots \ldots \ldots \ldots$

27 Screen R122: Select Type of Cost Analysis . . . . . . . . . . . . . 29

28 Sample Cost Results: Single Unit $\ldots \ldots \ldots \ldots \ldots \ldots \ldots \ldots \ldots \ldots \ldots$

29 Sample Cost Results: All Units Combined $\ldots \ldots \ldots \ldots \ldots \ldots \ldots \ldots \ldots$. 31

30 Screen R125: Save Total Cost Estimates $\ldots \ldots \ldots \ldots \ldots \ldots \ldots \ldots \ldots \ldots$

31 Screen R011: Retrieve Case Studies for Present-Worth Analysis ......... 34

32 Screen R013: Input Present-Worth Costing Parameters $\ldots \ldots \ldots \ldots \ldots \ldots$

33 Sample Present-Worth Results: Single Case Study $\ldots \ldots \ldots \ldots \ldots \ldots \ldots$

34 Sample Present-Worth Results: All Case Studies Combined ........... 37

35 Screen R012: Delete User-Created Files from Disk $\ldots \ldots \ldots \ldots \ldots \ldots \ldots$

A.1 Quick User's Chart of RECAP Input Screens $\ldots \ldots \ldots \ldots \ldots \ldots \ldots \ldots, 41$ 


\section{FOREWORD}

The software described in this report provides the U.S. Nuclear Regulatory Commission (NRC) with a capability to evaluate short-term replacement energy costs, including investigations into key sensitivities affecting these costs. These cost estimates were developed to assist in evaluating regulatory issues that potentially affect temporary reactor shutdowns or deratings.

NUREG/CR-5344 is not a substitute for NRC regulations, and compliance is not required. The approaches and/or methods described in this NUREG are provided for information only. Publication of this report does not necessarily constitute NRC approval or agreement with the information contained herein. 


\section{ACKNOWLEDGMENTS}

The authors would like to express their appreciation to Margaret Clemmons, Argonne National Laboratory (ANL), for editorial assistance and to the Information and Publishing Division Document Processing Center at ANL for word processing contributions. 


\title{
REPLACEMENT ENERGY COST ANALYSIS PACKAGE (RECAP): USER'S GUIDE
}

by

\author{
J.C. VanKuiken and D.L. Willing
}

\section{INTRODUCTION}

This report describes the installation and operating procedures to be used with the Replacement Energy Cost Analysis Package (RECAP), which estimates replacement energy costs for potential short-term shutdowns or deratings of 112 nuclear electricity-generating units in the United States. This microcomputer package was developed to assist the U.S. Nuclear Regulatory Commission (NRC) in applying the seasonal, unit-specific cost estimates for 1993-1996 that were developed in a previous replacement energy cost analysis (VanKuiken et al. 1992). ${ }^{1}$

Replacement energy cost refers to the change in generating-system production cost that results from shutting down a reactor. The change in production cost is determined from the difference between the total variable costs (variable fuel cost, variable operation and maintenance cost, and purchased energy cost) when the reactor is available for generation and when it is not.

Replacement energy costs were developed principally for the NRC to use in its regulatory impact analyses, specifically, those that examine proposed regulations requiring retrofitting or safety modifications of nuclear reactors. Such actions might necessitate shutdowns of nuclear power plants while changes are being implemented. As a tool for applying the seasonal cost estimates and sensitivity factors in VanKuiken et al. (1992), RECAP complements that report and allows the user to rapidly examine the cost trade-offs associated with short-term shutdown alternatives.

\subsection{MODEL ASSUMPTIONS}

The user is urged to review VanKuiken et al. (1992) in its entirety to fully appreciate the assumptions on which the replacement energy cost estimates used in RECAP are based. For example, care should be used in applying the estimates to shutdowns of a year or more because, in such cases, utilities would probably seek more-optimum solutions to the loss of a nuclear unit (e.g., increasing bulk power purchases from neighboring systems or decreasing firm energy sales). Long-term adjustments of this nature are not included in this analysis.

1 The results published in VanKuiken et al. (1992) cover a study period from 1992 to 1996 , but only the last four years (1993-1996) are included in RECAP. 
Similarly, care should be used in adjusting the assumed start-up dates for planned reactors (or restart dates for units that may have been temporarily shut down). Significant changes from the base-case assumptions could affect the original simulations of power pool operations, thereby influencing the base-case cost estimates. The RECAP help screens alert the user that changes such as these may affect the cost estimates.

Particular attention should be given to the assumptions affecting nuclear unit capacity factors. Several user options in RECAP directly or indirectly influence these factors. The default values (typically 62-65\%) reflect average annual availabilities and usage levels. This range of capacity factors accounts for planned outages for maintenance or refueling, unplanned (i.e., forced) outages, and other limitations related to system demand and operating constraints. In preparing case studies, the user should consider whether changes in start-up dates or general modifications of capacity factors are appropriate.

The cost calculations performed by RECAP are based on data obtained by the methods outlined in VanKuiken et al. (1992). To summarize those methods, seasonal replacement energy costs were derived from probabilistic production cost simulations of pooled utility-system operations. Factors affecting replacement energy costs, such as random unit failure probabilities for each generating unit, planned maintenance and refueling requirements, unit dispatching priorities, and system load characteristics, were treated in the simulations.

The original study also included the development of sensitivity estimates for (1) changes in fuel prices and (2) impacts of simultaneous shutdowns involving two or more reactors within each power pool. Fuel price sensitivities were examined only for oil and gas, not for nuclear or other fossil fuels.

At the time of the study described in VanKuiken et al. (1992), the average price for crude oil was approximately $\$ 20 / \mathrm{bbl}$ (or $\$ 3.50 / 10^{6} \mathrm{Btu}$ ), and the average cost for gas was $\$ 2.50 / 10^{6} \mathrm{Btu}^{2}$ With RECAP, the user can investigate the impacts of changing oil and gas prices by as much as $\pm 50 \%$ relative to these base-case assumptions. Thus, the user can examine price ranges of $\$ 10-\$ 30 / \mathrm{bbl}$ of oil $\left(\$ 1.75-\$ 5.25 / 10^{6} \mathrm{Btu}\right)$ and $\$ 1.25-\$ 3.75 / 10^{6} \mathrm{Btu}$ for natural gas.

The impact of simuitaneous shutdowns can be an important consideration if shutdown cases involving more than one reactor in a given power pool need to be examined. Sensitivity estimates were made in the original study to determine the relationships betweun the combined shutdown capacity and increases in replacement energy costs (in terms of botin total dollars and costs per kilowatt-hour needing to be replaced).

These relationships (between a shutdown of two or more reactors in a given power pool and the associated increases in costs) have been incorporated into RECAP. Replacement

2 Expressed in end-of-year (EOY) 1991 undiscounted dollars. These averages are approximate and are intended to be used only for reference. The replacement energy cost estimates used in RECAP are based on power-pool-specific fuel prices and use 1993 as the default reference year. 
energy cost results are automatically displayed with and without adjustments for multiple (i.e., simultaneous) shutdowns, so that the user can determine the incremental cost of simultaneous shutdowns, relative to individual reactor shutdowns.

For more detail regarding background assumptions, refer to VanKuiken et al. (1992). It provides further discussion and reference information on such items as cost assumptions, unit performance parameters, system generation and load characteristics, interpower-pool energy transfers, and fuel prices.

\subsection{OVERVIEW OF MODEL PERFORMANCE}

The model is typically used to study replacement energy costs under various shutdown or derating scenarios (referred to in this report as case studies) defined by the user. Menu-driven choices are provided for:

1. Reviewing the abstract of model and key assumptions,

2. Selecting reference-year dollars,

3. Adjusting fuel prices,

4. Reviewing base-case results for all units,

5. Selecting units for detailed cost analysis,

6. Analyzing the cost of those units selected under option 5, and

7. Analyzing the present worth of cases prepared under option 6.

In a typical session, the user (1) selects a set of units for analysis, (2) defines a shutdown (or derating) period, and (3) specifies changes in default capacity factors. The program then determines which seasonal cost numbers to apply, estimates total and daily costs, and makes the appropriate adjustments for multiple outages, if necessary.

Changes in reference-year dollars are based on gross national product (GNP) price deflators or on optional user inputs. Adjustments for changes in oil and gas prices are also based on user inputs. The adjustment factor selected by the user for increasing or decreasing oil and gas prices can be within $\pm 50 \%$. The same factor is applied to both fuel categories.

Once RECAP has completed the initial cost estimates for a case study (or a series of case studies), present-worth analyses can be conducted by using different reference-year dollars and discount rates, as specified by the user. The program uses default values for GNP price deflators, unless user-defined cost adjustment factors are entered.

In cases where the user is looking for less case-specific evaluations, RECAP also provides a review option for scanning the seasonal costs ( $\$ /$ day) for each unit. This option 
is useful for a rapid review of cost sensitivities as a function of season and reactor, but it does not require the user to specify the shutdown length or other outage parameters.

\subsection{REPORT ORGANIZATION}

This report is organized as follows. Section 2 describes the installation procedures for RECAP, and Sec. 3 covers operating procedures, including several flow diagrams, which illustrate the organizational logic of the model, and a complete set of program screens to help the user understand and select various model options. 


\section{MICROCOMPUTER INSTALLATION PROCEDURES}

This section describes the procedures for installing and beginning execution of RECAP on a personal computer (PC). Instructions are given for installing RECAP on a hard disk (required), which provides fast operation and sufficient capacity to store the results. Staff members of the NRC who would like further information and/or program disks should contact the NRC Office of Nuclear Regulatory Research, Division of Regulatory Applications.

\subsection{HARDWARE REQUIREMENTS}

The following hardware is required to run RECAP:

1. An IBM or IBM-compatible PC, XT or higher, with 1.7 MByte or more of hard disk space;

2. A color monitor (preferable); and

3. A printer (to obtain printouts of RECAP results).

\subsection{SOFTWARE REQUIREMENTS}

The only software requirement is that DOS 3.1 or higher is loaded on the user's machine. If problems are encountered in running RECAP after the installation instructions have been followed, the user should ascertain that no memory-resident programs (such as SIDEKICK) are installed on the machine.

\subsection{INSTALIATION PROCEDURES}

All user input instructions are shown in bold print. Press the $<$ ENTER $>$ key after each line of instruction.

1. Create a RECAP subdirectory on the machine. At the $\mathrm{C}: \backslash>$ prompt, type:

\section{C: $1>$ MD RECAP}

2. Change to the RECAP subdirectory. At the $\mathrm{C}: 1>$ prompt, type:

\section{C: $\backslash>$ CD RECAP}

3. Incert the RECAP program diskette into the appropriate floppy drive (A: or B:). For purpose of instruction, we assume you are working from the $A: 1>$ drive. If you are using a different drive, simply substitute that letter in the instructions wherever you see $A: \backslash>$ referenced. At the C: \RECAP> prompt, type:

C: \RECAP>COPY A:** 
4. RECAP is now installed and ready to execute.

5. To run RECAP, move to the subdirectory that contains the RECAP files. If this step is done immediately after installation, you are already in the correct directory. Otherwise, type:

\section{C: $\backslash>$ CD \RECAP}

\section{C: $\backslash$ RECAP $>$ RECAP}

The introductory RECAP screen shown in Fig. 1 will appear.

6. Press the F10 key (as indicated on screen R005, Fig. 1) to begin data loading. The program pauses as it reads all of the input data required for the cost analyses. ${ }^{3}$ Following this pause, the main menu of RECAP program options appears. For further operating instructions, refer to Sec. 3.

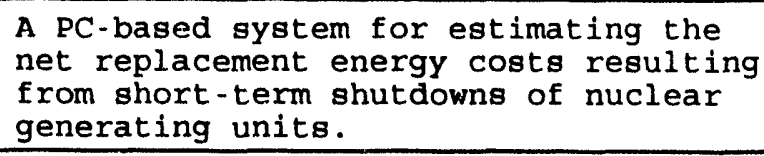

by

Argonne National Laboratory

Energy and Environmental Systems Division February 1994 Update

Press "ESC" to return to DOS or press "F10" to continue with RECAP.

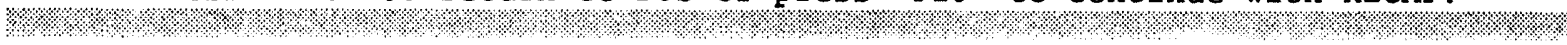

3 The length of this pause depends on the machine speed. For reference, 1 minute is typical for a 286 machine, 10 seconds for a 386 , and 3 seconds for a 486 . 


\section{OPERATING PROCEDURES}

Once the steps outlined in Sec. 2.3 have been completed, RECAP is ready for execution. This section first provides some general information regarding function keys, help facilities, and screen format and then explains how to move through the basic program options. Flowcharts of the overall program logic and sequencing are included, together with a complete set of input screens.

\subsection{FUNCTION KEYS AND SCREEN FORMAT}

\subsubsection{Help Options}

Two types of built-in help facilities are provided in RECAP to aid the user with explanations and definitions. These help options can be accessed by pressing the F1 and F2 function keys:

- F1: Provides keystroke help for the basic keyboard operating procedures used in RECAP.

- F2: Provides screen text to assist the user with application-related questions and definitions.

A few of the keystroke conventions described in the help information accessed by pressing F1 are especially important in obtaining the proper program responses. These conventions are described in Sec. 3.1.2.

\subsubsection{Use of the ENTER, F10, and ESCAPE Keys}

As the user responds to prompts from RECAP, three keys are especially important to understand and use: ENTER, F10, and ESCAPE.

An important distinction is made in RECAP between (1) entering data in a data entry field and (2) accepting all data entered on a screen. The ENTER key is used to complete a response to a screen prompt or a data entry field. The F10 key is used to accept all of the inputs made on a screen. On a few screens, pressing ENTER after the last data prompt is interpreted the same as F10, and RECAP accepts the data and continues to another screen. In most cases, however, pressing ENTER at this point (and continuing to press it) only cycles the cursor back through the data entry fields on the same screen to allow additional modifications until the user is satisfied that all of the entries are correct. The F10 key must then be pressed to accept the inputs and move to another screen. 
Pressing the ESCAPE key (designated in this report as ESC) signals RECAP to ignore the inputs on the current screen and return to the previous screen so that the user can correct errors or make other modifications to that screen. To revisit earlier screens, the ESC key can be pressed more than once; each time the user is returned to a previous screen. In this way, the ESC key can be used to return to the main menu from any point in the program. However, in most cases, the data entries on the screen from which ESC was pressed are not saved and must be reentered when the user returns to that screen. ${ }^{4}$

\subsubsection{Screen-Dependent Function Keys}

Many of the RECAP menus define the function keys F4-F9 for special purposes on a particular screen. The screen-dependent functions are defined at the bottom of each display screen, and expanded explanations are usually available by pressing F 2 for the accompanying screen help.

Figure 2 illustrates a typical screen layout that includes a number of screen-dependent functions at the bottom. While the main menu covers the selection criteria for the reactors in the case to be studied, the function keys provide additional support

Select Units for Analysis

RO20

There are \% generating units currently selected for subsequent cost analysis. You may now specify additional criteria to reduce the size of this list.

\begin{tabular}{ll}
\hline 1. Unit name & 6. Reactor supplier \\
2. Utility name & 7. Turbine supplier \\
3. Reactor type & 8. Architect engineer \\
4. Power pool number & 9. Constructor \\
5. NERC region & \\
\hline
\end{tabular}

Choose a unit-selection criterion: (1-9, frum above list)

Press "F5" to restore all units to the current list.

Press "F6" to review currently selected units in brief.

Press "F7" to review currently selected units in detail.

Press "F1" for keystroke help, or "F2" for screen help.

Press "ESC" to return to the main RECAP menu (begin cost analysis).

Press "F10" to accept selection and continue screening.

\%.\%.

FIGURE 2 Sample Screen Layout Showing Screen-Dependent Function Keys

4 The one exception to this rule is described at the end of Sec. 3.7.3. In the special context of selecting units for analysis, the ESC key performs a normal exiting function, while retaining user inputs that have been made to designate the type of units to be analyzed. 
options. For example, the F5 key can restore all units to the case-study list if the user realizes that some units have been eliminated inadvertently. In addition, the F7 key can review unit-specific details on reactor size and type, fuel costs, utility owner(s), and other key characteristics.

The user should read the screen-dependent function definitions for each display screen. These functions have been designed to facilitate use of the program.

\subsubsection{Error Message Line}

The boitom line of each RECAP display is reserved for special case-dependent messages. The line appears with an accompanying tone to alert the user to particular conditions or errors. For example, when RECAP is first executed, a line appears at the bottom of the first screen to let the user know that a pause is occurring as the program loads the data into memory. Similarly, error messages appear if the user attempts to enter invalid data, such as alphabetical characters in data fields that call for numerical entries. In most cases, the user is instructed to press any key before continuing.

\subsubsection{Screen Reference Numbers}

Each RECAP input screen or menu has been labeled with a unique "Rnnn" number to thelp in referencing the screens in this report and from within the program. These numbers are for reference only and do not necessarily correspond to the sequence in which the screens appear. For the user's convenience, the appendix provides a diagram showing all screens by reference number in their appropriate operational sequence.

\subsection{OVERVIEW AND FLOWCHARTS OF THE PROGRAM OPTIONS IN THE MAIN MENU}

Figure 3 shows the main RECAP menu (Screen RC10). This menu presents the user with seven basic options for defining case studies and performing cost analyses:

1. Reviewing the RECAP abstract and assumptions,

2. Selecting reference-year dollars for reporting the results from option 6 ,

3. Adjusting fuel prices for the case to be analyzed,

4. Reviewing the base-case results from VanKuiken et al. (1992) (these will be adjusted to reflect any changes made by the user in options 2 and 3),

5. Selecting reactor units for the case to be analyzed,

6. Performing one or more energy replacement cost analyses, and 
RECAP: Replacement Energy Cost Analysis Package - MAIN MENU

R010

You may now select a basic RECAP function.

1. Review abstract of model and key assumptions

2. Select reference year dollars

3. Adjust fuel prices

4. Review base-case results for all units ( $\$$ thousand/day)

5. Select unit(s) for detailed cost analysis

6. Perform cost analysis (for units selected in option 5)

7. Perform present worth analysis (for cases prepared in option 6)

Select a function: 糸 $(1-7$, from above 1 ist)

Press "F1" for keystroke help, or "F2" for screen help.

Press "ESC" to return to previous menu.

Press "F10" to continue.

FIGURE 3 Screen R010: Main RECAP Menu

7. Performing a present-worth analysis for one or more case studies (completed in option 6).

Figures 4-7 illustrate these options and the related pathways available in RECAP.

Options 1 and 4 enable the user tn review text descriptions of the model functions and base-case results, but they offer no computational choices (except that any user inputs for options 2 and 3 are reflected in the costs that can be reviewed in option 4). Options 2 and 3 allow some modifications in reference-year dollars and oil and gas price assumptions. These first four menu options are briefly described in Secs. 3.3-3.6. Further information about these options can be obtained from within RECAP by pressing the F2 key for screen help.

Options 5-7 cover the tasks of (1) selecting units for study, (2) defining and completing cost analyses, and (3) conducting present-worth analyses, respectively. These options are discussed in detail in Secs. 3.7-3.9. Section 3.11 explains how to use the options to investigate cases in which several shutdowns would occur within a single power pool that overlap rather than occur simultaneously (the latter case is handled automatically in option 6). Finally, the procedures for deleting files and exiting RECAP are given in Secs. 3.10 and 3.12 , respectively.

From any point in the program, the ESC key can be used to return to the main menu, by means of the procedure explained in Sec. 3.1.2. Keys F1 and F2 provide keyboard and screen assistance, respectively. 


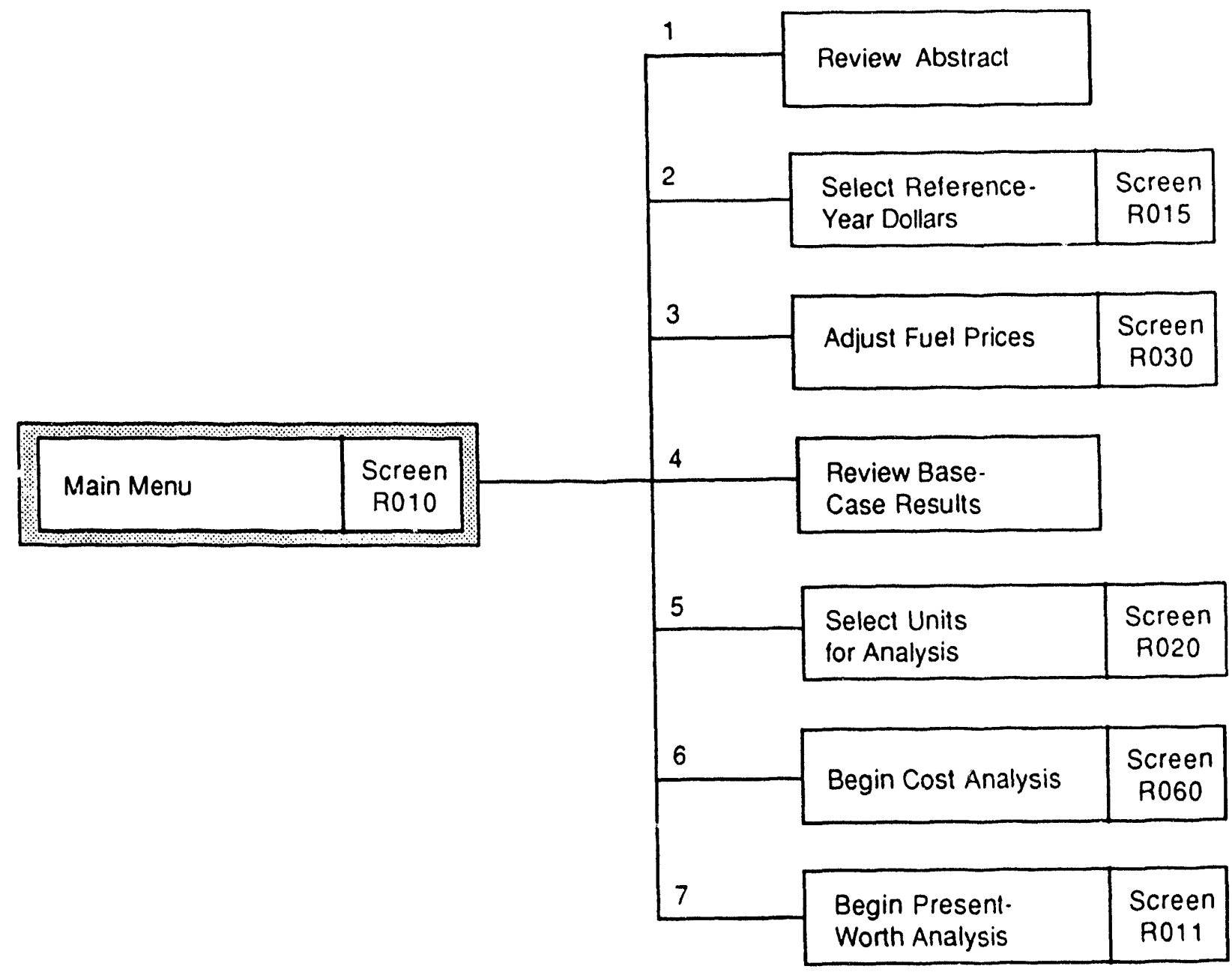

FIGURE 4 Program Flowchart: Main RECAP Menu

\subsection{OPTION 1: REVIEWING THE RECAP ABSTRACT AND ASSUMPTIONS}

Option 1 on the main menu (Fig. 3) provides introductory information to help the user understand the scope of the initial analysis and the basic functions available in RECAP. This option is strictly text material for review. While the text is on-screen, it can be printed by pressing the asterisk $\left(^{*}\right)$ key, followed by a 1 to print the current page or a 2 to print the entire document. The PgUp and PgDn keys can be used to scan through the text, and the ESC key can be used to exit the abstract review and return to the main RECAP menu. For a more detailed description of the methods and assumptions provided in option 1, refer to VanKuiken et al. (1992).

\subsection{OPTION 2: SELECTING REFERENCE-YEAR DOLLARS}

Option 2 on the main menu (Fig. 3) allows the user to select a different reference year for displaying all cost estimates. The default is to present results in 1993 undiscounted 


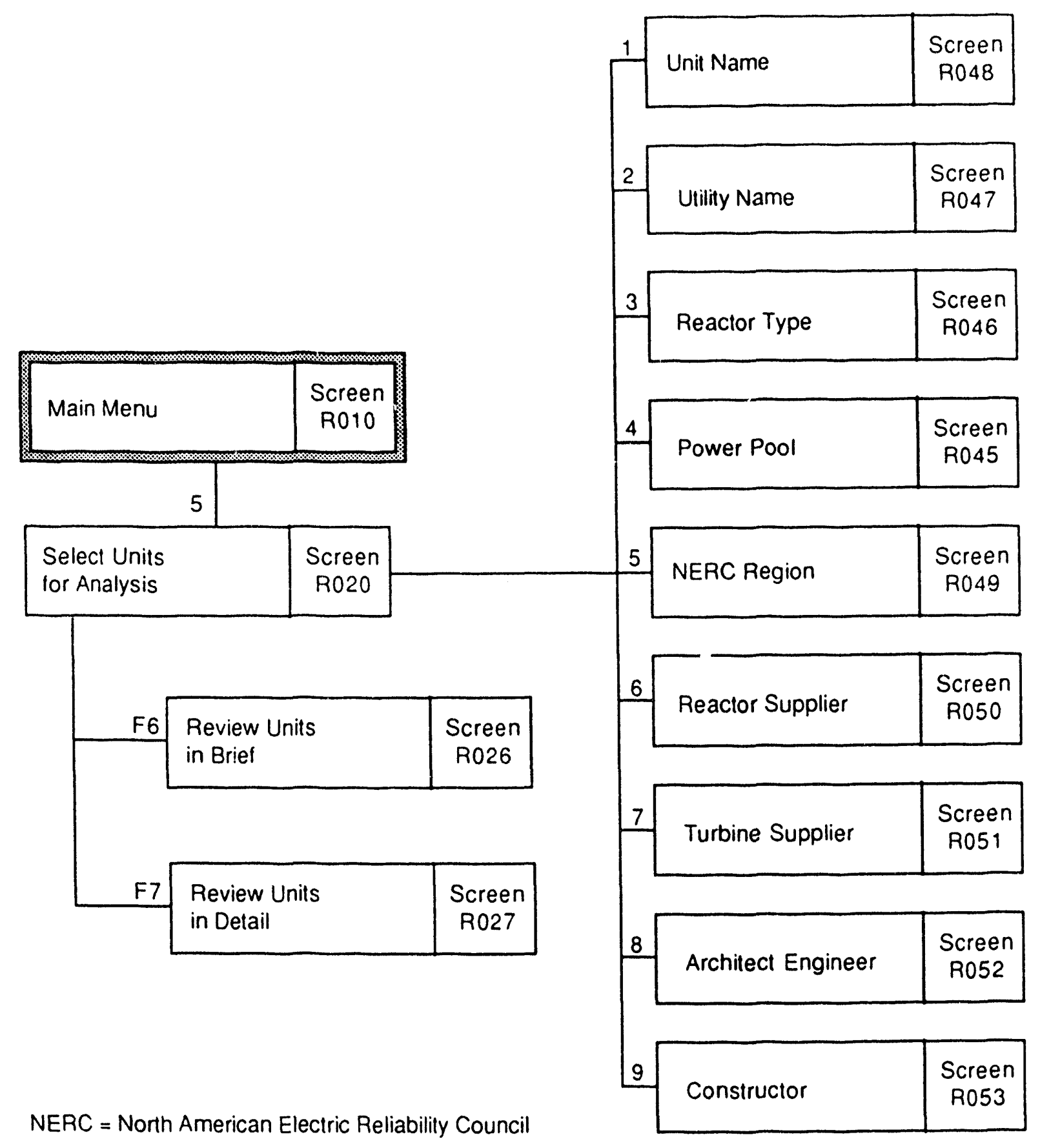

FIGURE 5 Program Flowchart: Unit Selection Criteria 


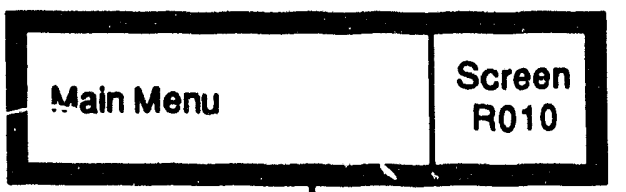

6

\begin{tabular}{|l|l|}
\hline $\begin{array}{l}\text { Specity Shuldown or } \\
\text { Derating Schedule }\end{array}$ & $\begin{array}{c}\text { Screen } \\
\text { R060 }\end{array}$ \\
\hline
\end{tabular}
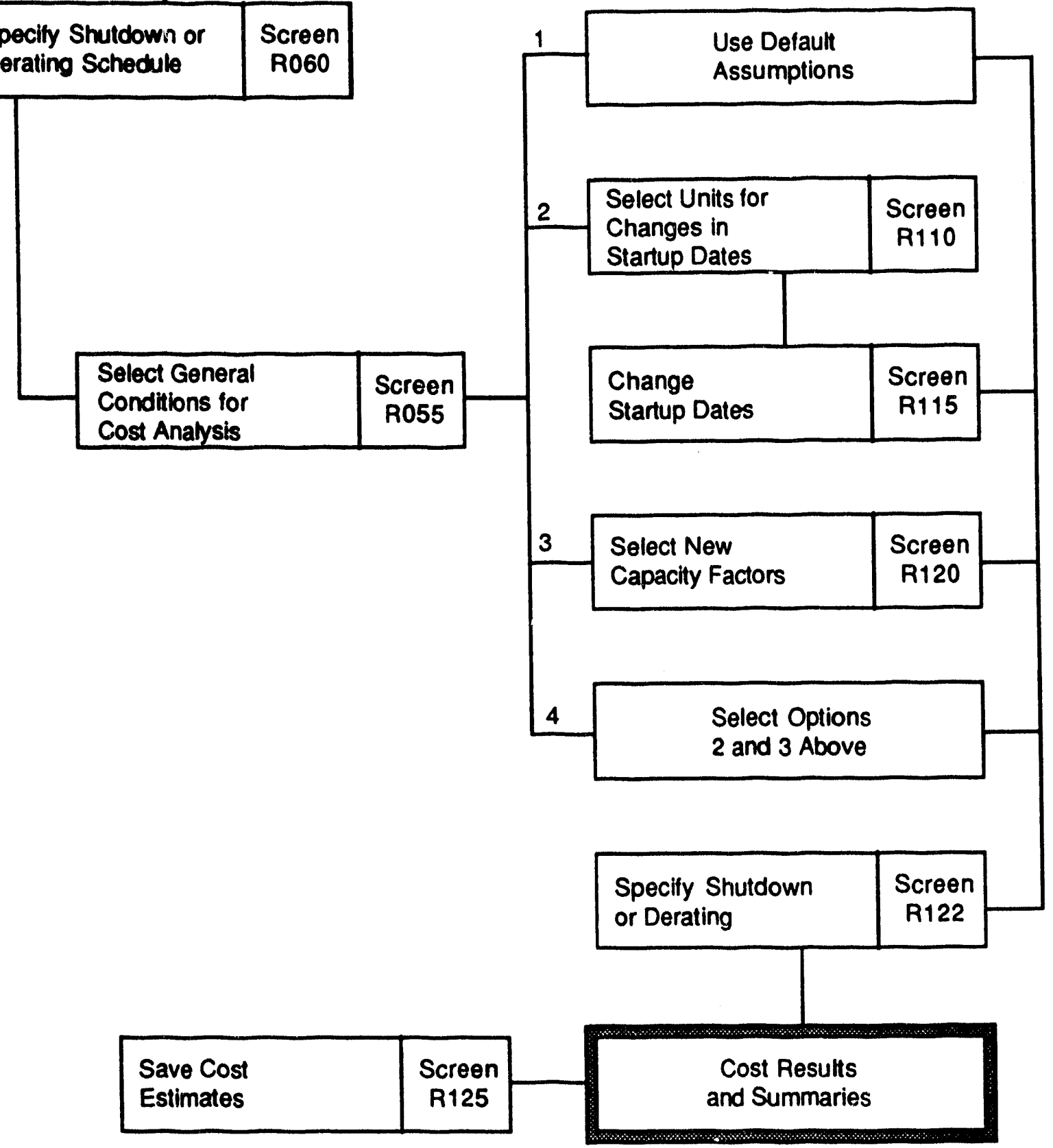

FGURE 6 Program Flowchart: Replacement Bnergy Cost Analysis 


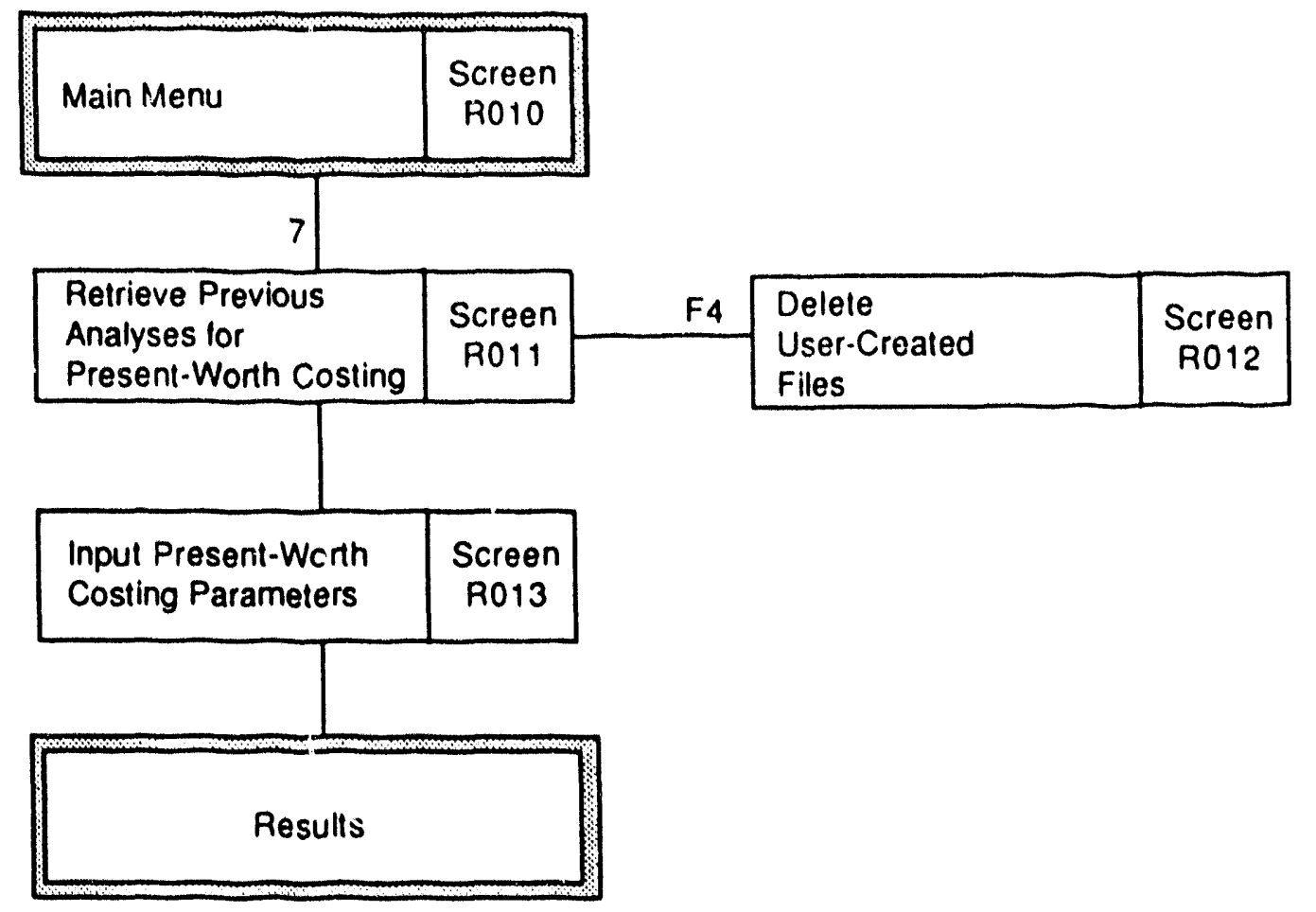

FIGURE 7 Program Flowchart: Present-Worth Analysis

dollars. Selecting option 2 from the main menu brings up Screen R015 (Fig. 8), which prompts for any change in reference-year dollars.

Screen R015 displays the GNP price deflators for 1989-1993. These default cost multipliers can be used in selecting a reference year, or the user can override the defaults with inputs from the keyboard. The help feature for Screen R015 gives a brief example of how cost adjustments are made. Once a reference year is selected, RECAP converts all cost estimates according to the specified index, until the user (1) returns to Screen R015 (Fig. 8) and modifies the assumption or (2) performs a present-worth analysis, described in Sec. 3.9.

\subsection{OPTION 3: ADJUSTING FUEL PRIC.3S}

Because of fluctuations and uncertainties in fuel prices, particularly in oil and gas prices, option 3 was designed to permit the modeling of alternative price assumptions. The assumed prices for fossil fuels directly affect the estimates of shutdown costs. In the original study by VanKuiken et al. (1992), fuel prices were based on historical power pool averages for each of the major fuel categories, such as bituminous and subbituminous coal, residual and distillate oil, and natural gas. 


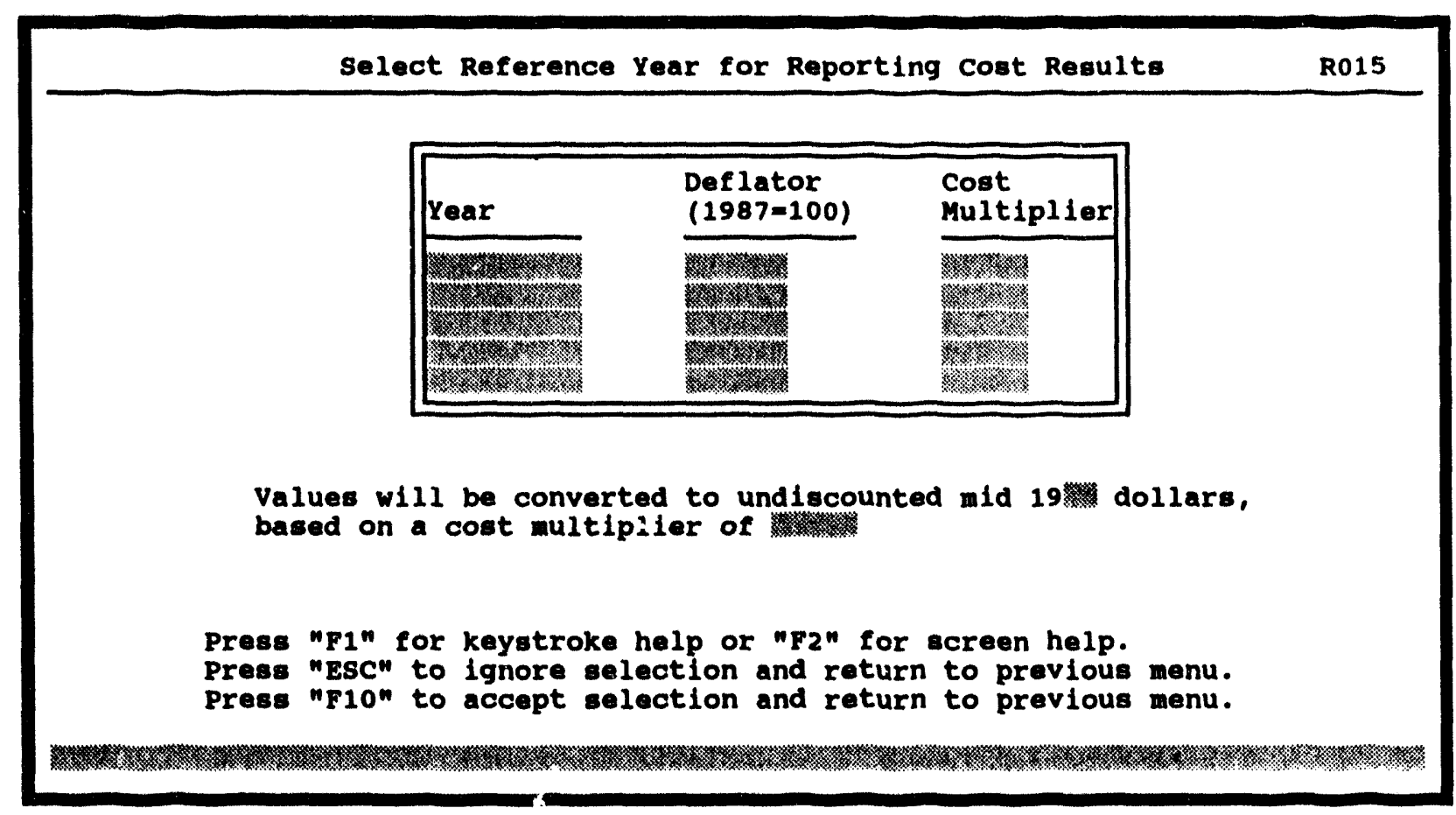

FIGURE 8 Screen RO15: Select Reference Year for Reporting Cost Results

The pool-specific fuel prices used as a base case reflect an average price of approximately $\$ 20 / \mathrm{bbl}$, or $\$ 3.50 / 10^{6} \mathrm{Btu}$, for crude oil and $\$ 2.50 / 10^{6} \mathrm{Btu}$ for natural gas (in EOY 1991 undiscounted dollars). While coal prices have remained relatively stable in the recent past, oil and gas prices have shown significant variations (DOE 1985-1991). For example, the average cost of oil between 1983 and 1991 ranged from a high of $\$ 30 / \mathrm{bbl}$ in 1984 to a low of about $\$ 15 / \mathrm{bbl}$ in 1988 (current-year dollars). These fluctuations directly influence the replacement energy costs for reactor shutdowns or deratings.

RECAP enables the user to explore the effects of other fuel prices on replacement energy costs. The internal calculations involved are based on a series of sensitivity analyses that were part of the VanKuiken et al. (1992) study. The sensitivity tests consisted of making changes in the presumed price of oil and natural gas over a range of $\pm 50 \%$ relative to the base-case values. It is important to note that these sensitivity tests, and the associated options in RECAP, correspond to simultaneous and identical percentage changes in oil and gas prices, not to independent variations in these prices.

Selecting option 3 from the main menu (Fig. 3) brings up Screen R030, shown in Fig. 9, which prompts for a value between $+50 \%$ (for price increases) and $-50 \%$ (for price decreases). These boundary values reflect the approximate range of validity that was estimated for the original sensitivity parameters. Once a value has been specified, it remains in effect for all subsequent case studies until the user (1) exits RECAP or (2) returns to the main menu and reselects option 3 to make additional changes. 
You may now select an oil and gas price increase or decrease that will affect all subsequent pricing calculations (the same adjustment factor will be applied to the assumed prices of both 011 and gas).

The initial cost results are based on pool-specific fuel prices that reflect an approximate average of $\$ 20 /$ barrel or $\$ 3.50 / \mathrm{MmBtu}$ for crude o11, and $\$ 2.50 / 20$ Btu for natural gas.

INCREASE in 011 and gas prices: (use negative for price DECREASE)

Press "F1" for keystroke help, or "F2" for screen help.

Press "ESC" to ignore changes and return to previous menu.

Press "FIO" to save changes and return to previous menu.

FTGURE 8 Screen R030: Make Fuel Price Adjustmente

\subsection{OPTION 4: REVIEWING DASE-CASE RESULTS}

Option 4 on the main menu (Fig. 3) allows the user to scan the base-case shutdown costs from VanKuiken et al. (1992), expressed in thousands of dollars per day for each unit, with adjustments made for user-specified changes in reference-year dollars and/or fuel prices (options 2 and 3, respectively). The results are displayed in a tabular format that can be scanned with the $\mathrm{PgUp}$ and $\mathrm{PgDn}$ keys. Alternatively, the user can move to a specific page by entering the desired page number.

The results are displayed in a sequence of two pages per screen of unit names. The first page contains the results for 1993-1994, and the second page displays the results for the same units for 1995-1996. Therefore, the user must press the PgDn key twice to advance to a new list of units. While the base-case results are on-screen, they can be printed by pressing the asterisk key, followed by a 1 to print the current page only or a 2 to print the entire document. The review mode does not provide calculation capabilities.

\subsection{OPTION 5: SELECTING UNITS FOR ANALYSIS}

Option 5 on the main menu (Fig. 3) enables the user to select the nuclear reactors for the case study (or group of case studies) to be performed. If this option is not executed before proceeding with the cost analyses in option 6, all 112 reactors will be included in the cost calculations. To select a smaller group of reactors for study, nine selection criteria are available through Screen R020 (Fig. 10), which appears after option 5 is selected from the 
main menu. How to move through the pathways associated with these criteria (see Fig. 5), and obtain help or reference information, is described below.

\subsubsection{Screen-Specific Help Meseages}

Screen-specific help messages are available for each of the nine selection criteria. After the screen corresponding to a given criterion has been called up, the user can press F2 to obtain the associated help message. In addition to explaining the specific screening logic for each criterion, these help messages contain important reference information, such as tables of abbreviations used in the screens.

\subsubsection{Reactor-Specific Reference Data}

Reactor-specific reference data are available for review at any time by pressing either F6 or F7 from Screen R020 (Fig. 10). Key F6 provides a brief review of the currently selected list of units (i.e., all units meeting any criteria selected so far, or all 112 units if no criteria have been selected). Key F7 provides a detailed review of the units. Figure 11 (Screen R026) shows the format for the brief review. For each selected unit, the display shows the name, an indication of whether or not the unit is owned jointly, the utility name (licensee or major owner for jointly owned units), and the power pool affiliation. To review lists that are longer

Select Units for Analysis

R020

There are You may now specify additional criteria to reduce the size of this list.

\begin{tabular}{ll}
\hline 1. Unit name & 6. Reactor supplier \\
2. Utility name & 7. Turbine supplier \\
3. Reactor type & 8. Architect engineer \\
4. Power pool number & 9. Constructor \\
5. NERC region & \\
\hline
\end{tabular}

Choose a unit-selection criterion: 㬎 (1-9, from above list)

Press "F5" to restore all units to the current 1 ist.

Press "F6" to review currently selected units in brief.

Press "F7" to review currently selected units in detail.

Press "F1" for keystroke help, or "F2" for screen help.

Press "Esc" to return to the main RECAP menu (begin cost analysis).

Press "Fio" to accept selection and continue screening. 


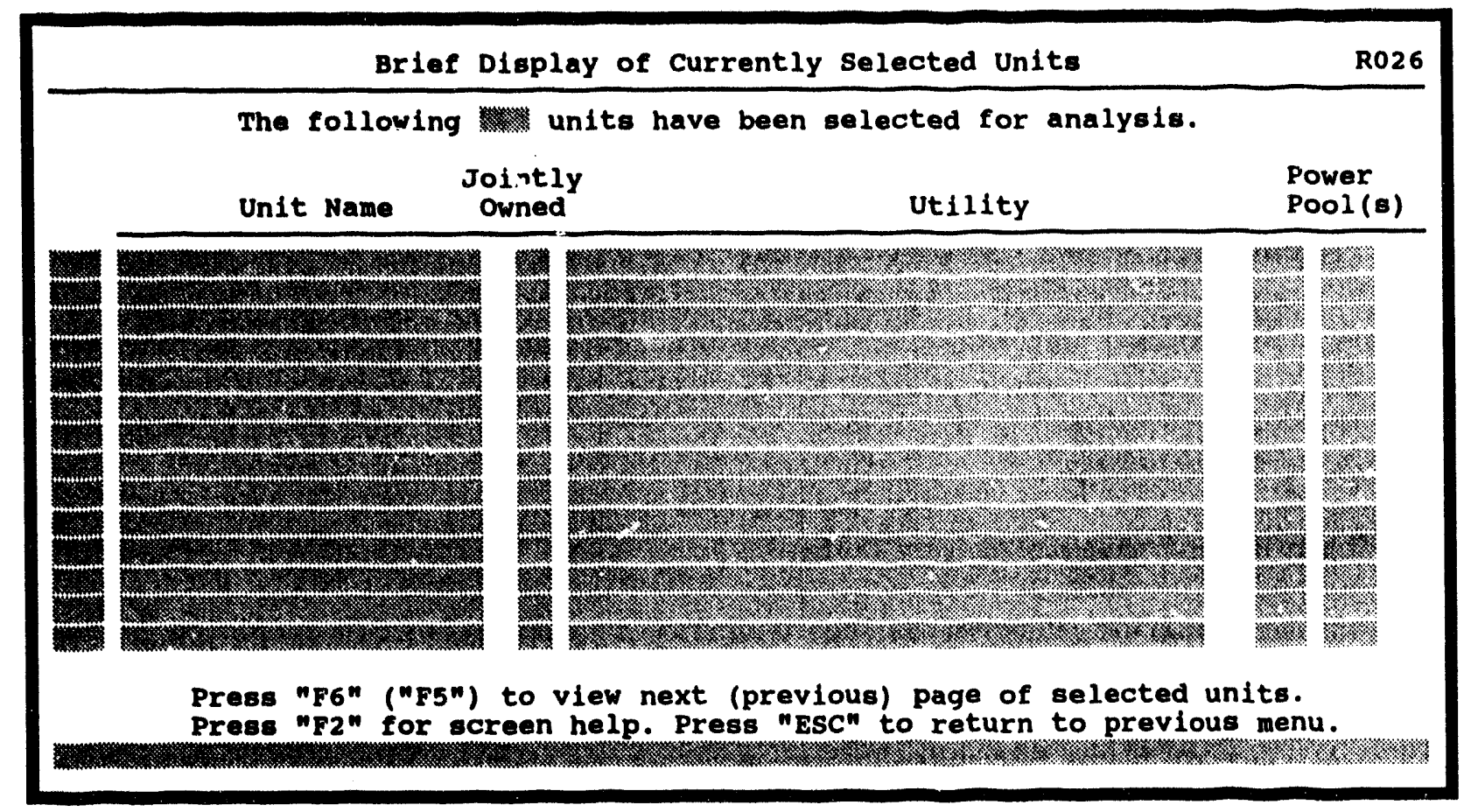

\section{FIGURE 11 Screen R026: Brief Display of Currently Selected Units}

than a single display screen, the user can press F6 to advance to the next set of units or F5 to return to the previous set.

The format for the detailed review is shown in Fig. 12 (Screen R027). One-screen summaries are provided for each reactor selected for analysis. The display includes unit characterization data such as unit size, heat rate, variable fuel cost, and reactor type. Also shown are other data that may be important for the selection process, such as utility names (up to six joint owner names), turbine supplier, constructor, and architect engineer. To scan through these review displays, the user presses either F6 to advance to the next page or F5 to return to the previous page (the $\mathrm{PgDn}$ and $\mathrm{PgUp}$ keys are not functional from these screens).

\subsubsection{Selection Procedure}

Figures 13-21 show the screen layouts for each of the nine selection crittria. These criteria function on a "cumulative" basis, meaning that as more criteria are selected, fewer units remain on the list for subsequent cost analysis. Each additional round of screening operates on the set of units remaining from the previous round of screening. Before performing the unit selection procedure, the user should review Sec. 3.1.2, which describes the use of the ENTER, F10, and ESC keys. 
Detailed Review of Currently selected Units

The following units have been selected for analysis.

Unit Name: NERC Region:

Power Pool:

Heat Rate (Btu/kWh):

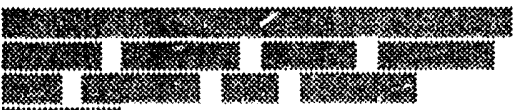

Unit ID: Unit size (WW): Variable Fuel Cost:

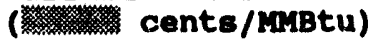

Ut11ity:

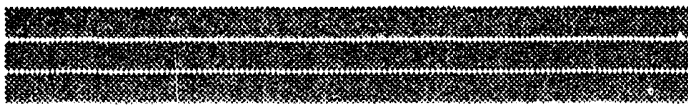

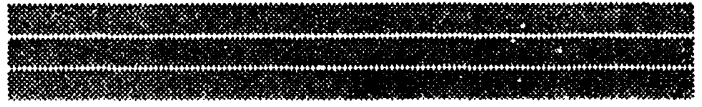

Reactor Type: Turbine Supplier: Construction stage: original operation:

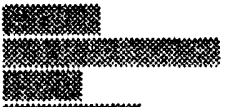

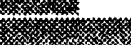

Reactor Supplier: Architect Engineer: Constructor: Actual operation:

Press "F1" for keystroke help, or "F2" for screen help.

Press "F6" ("F5") to view next (previous) page of selected units.

Press "F8" ("F7n) to view 10 units ahead (behind) current unit.

Press "ESC" to return to previous menu.

.

\section{FIGURE 12 Screen R027: Detailed Review of Currently Selected Unite}

Select Units by Name

You may now (de) select units for analysis from the following list.

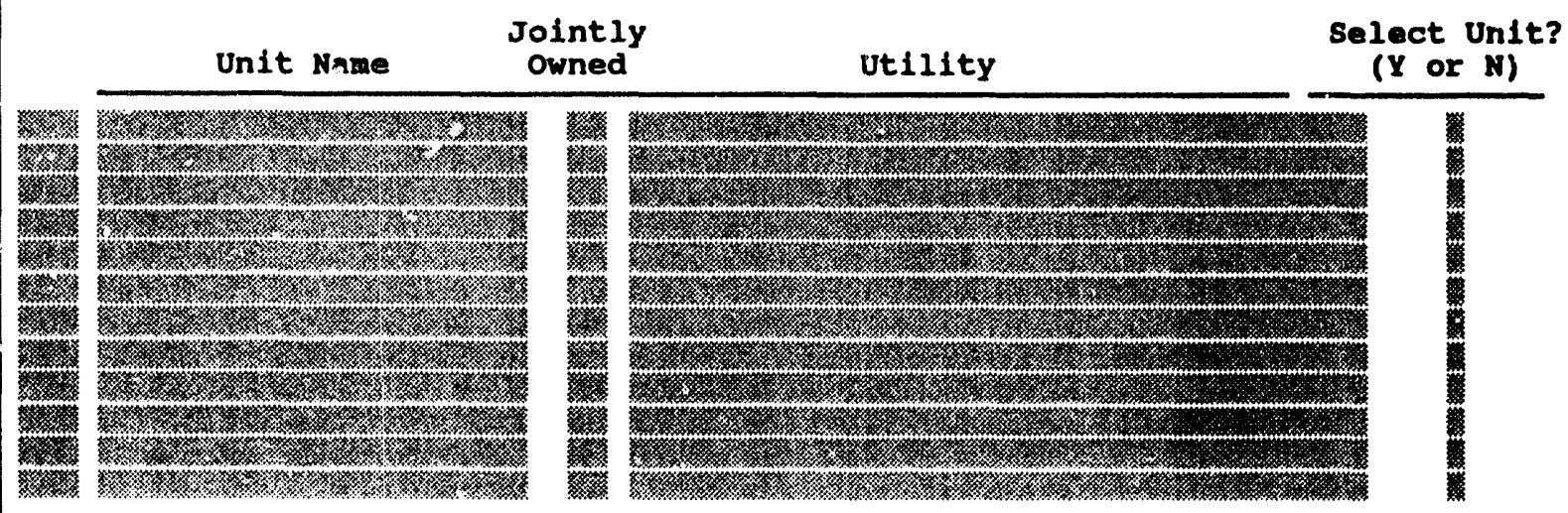

Press "F6" ("F5") to view next (previous) page of units.

Press "F1" for keystroke help, or "F2" for screen help.

Press "ESC" to ignore selection changes and return to previous menu.

Press "F10" to accept changes and return to previous menu.

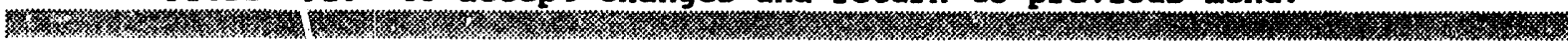

FIGURE 13 Screen R048: Select Units by Name 
Select Units by Utility

R047

You may now select utilities in order to reduce the list of selected units. Note: Press "F2" for comments regarding jointly owned units.

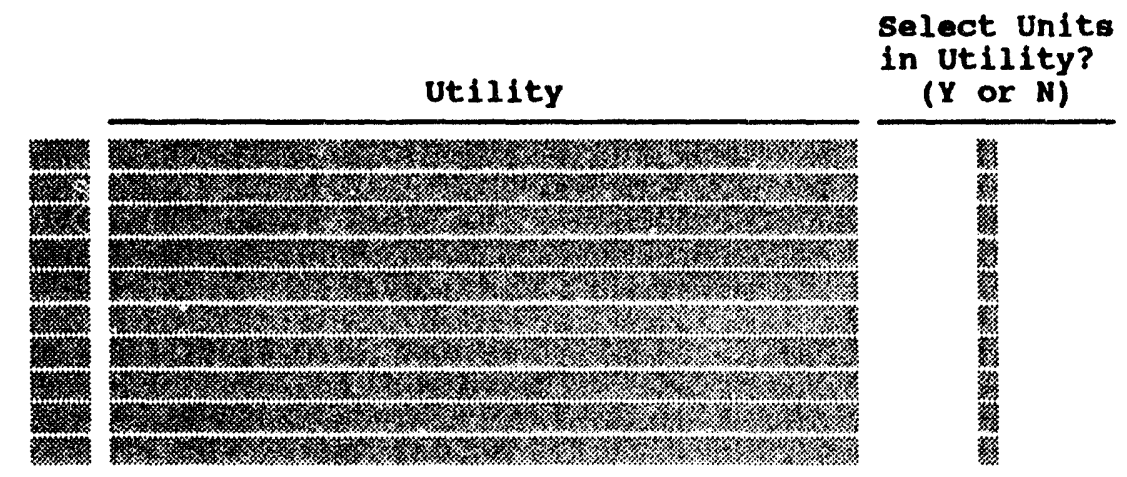

Prese "F6" ("F5") to view next (previous) page of utility names.

Press "F1" for keystroke help, or "F2" for screen help.

Press "EsC" to Ignore selection changes and return to previous menu.

Press "F10" to accept changes and return to previous menu.

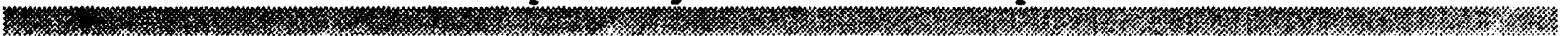

FIGURE 14 Sereen R047: Select Units by Utility

geleot onite by neactor rype

2046

Iou may seleat reactor types in order to reduce the liat of geleat sd units.

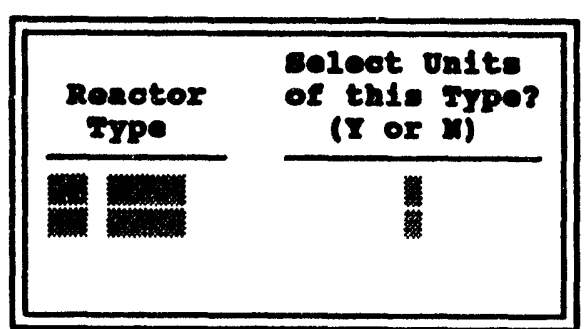

(PWR = presourised weter reactor: BWR = bol11ng water renotor)

preae "ri" for keyatroke help, or "ran for eoreen help.

prean mecen to 1guore celeotion obanges and return to provioun nonu.

prese "Fio" to acoept ohanges and return to provious nonu.

FGURE 15 Screen R046: Select Units by Reactor Type 
Select Units by Power Pool

You may now select power pools in order to reduce the list of selected units.

\begin{tabular}{|c|c|}
\hline $\begin{array}{l}\text { Power } \\
\text { Pool }\end{array}$ & $\begin{array}{c}\text { Select Units } \\
\text { in this Pool? } \\
\text { ( } Y \text { or } N)\end{array}$ \\
\hline 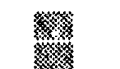 & 墒 \\
\hline 玹 & 濯 \\
\hline 现 & 㛑 \\
\hline 格汶 & 瓷 \\
\hline . & 皪 \\
\hline & \\
\hline
\end{tabular}

Press "F6" ("F5") to view next (previous) page of power pools.

Press "F1" for keystroke help, or "F2" for screen help.

Press "ESC" to ignore selection changes and return to previous menu.

Press "F10" to accept changes and return to previous menu.

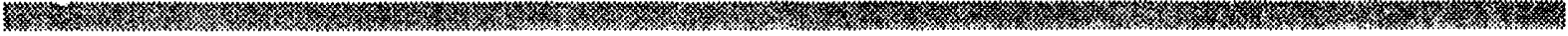

\section{FIGURE 16 Screen R045: Select Units by Power Pool}

Select Units by NERC Region

R049

You may now select NERC regions in order to reduce the list of selected units.

\begin{tabular}{|c|c|c|}
\hline \multicolumn{2}{|c|}{ NERC Region } & $\begin{array}{c}\text { Select NERC } \\
\text { Reglon? } \\
\left(\begin{array}{l}\mathrm{X} \text { or } \mathrm{N})\end{array}\right.\end{array}$ \\
\hline 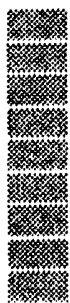 & 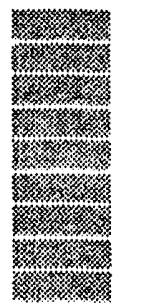 & 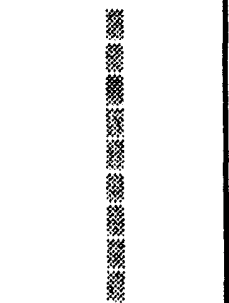 \\
\hline
\end{tabular}

Press "F1" for keyatroke help, or "F2" for screen help.

Press "ESC" to ignore selection changes and return to previous menu.

Press "F10" to accept changes and return to previous menu.

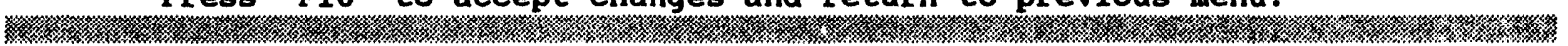

FIGURE 17 Screen R049: Select Units by North American Electricity Reliability Council Region 
Select Units by Reactor Supplier

R050

You may now select reactor suppliers to reduce the list of selected units.

\begin{tabular}{|lc|}
\hline Reactor supplier & $\begin{array}{c}\text { Select Reactor } \\
\text { Supplier? } \\
\text { (Y or } N)\end{array}$ \\
& \\
\hline
\end{tabular}

Press "F1" for keystroke help, or "F2" for screen help.

Press "ESC" to ignore selection changes and return to previous menu.

Press "F10" to accept changes and return to previous menu.

\%w.

\section{FIGURE 18 Screen R050: Select Units by Reactor Supplier}

Select Units by Turbine Supplier

R051

You may now select turbine suppliers to reduce the list of selected units.

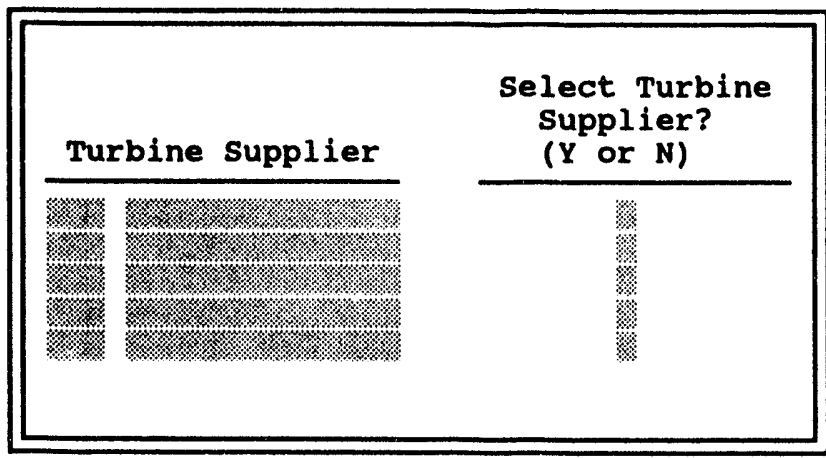

Press "F1" for keystroke help, or "F2" for screen help.

Press "ESC" to ignore selection changes and return to previous menu. Press "F10" to accept changes and return to previous menu.

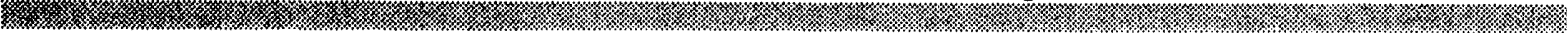

FIGURE 19 Screen R051: Select Units by Turbine Supplier 
Select Units by Architect Engineer

R052

Yisu may now select architect engineers to reduce the list of selected units.

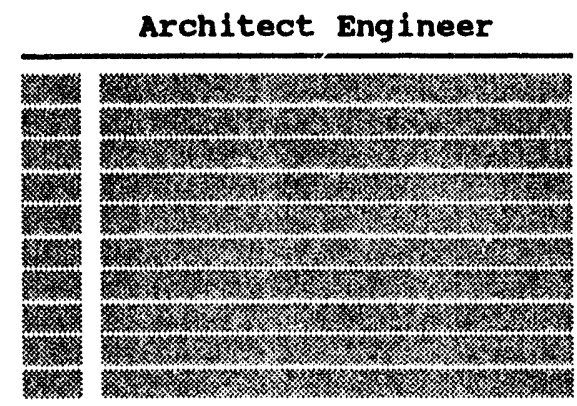
Select Architect Engineer?
( $Y$ or $N$ )

Press "F1" for keystroke help, or "F2" for screen help.

Press "F6" ("F5") to view next (previous) page.

Press "ESC" to ignore selection changes and return to previous menu.

Press "F10" to accept changes and return to previous menu.

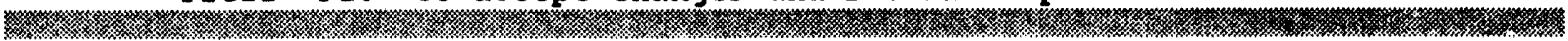

FIGURE 20 Screen R052: Select Units by Architect Engineer

Select Units by Constructor

R053

You may now select constructors to reduce the list of selected units.

Select

Constructor?

Constructor

( $\mathrm{Y}$ or $\mathrm{N}$ )
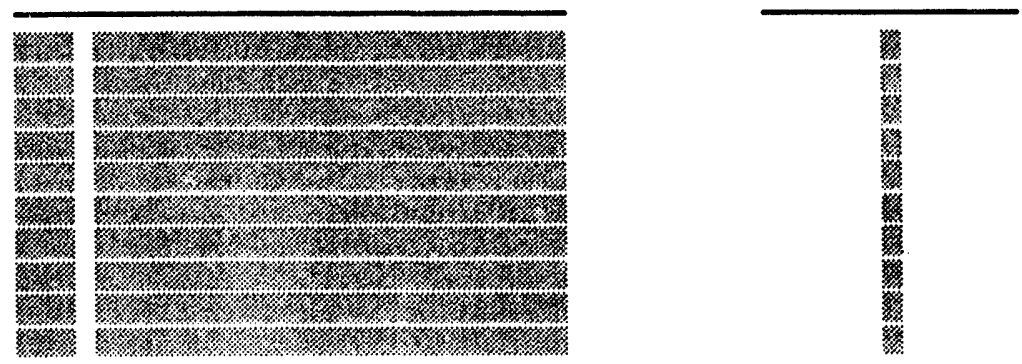

Press "F1" for keystroke help, or "F2" for screen help.

Press "F6" ("F5") to view next (previous) page.

Press "ESC" to ignore selection changes and return to previous menu.

Press "F10" to accept changes and return to previous menu.

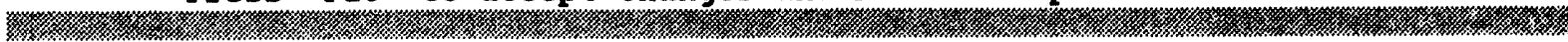

FIGURE 21 Screen R053: Select Units by Constructor 
For example, if the user is interested in analyzing shutdown costs for all boiling water reactors (BWRs) constructed by Burns \& Roe, Inc. (abbreviated B\&R as shown in the help screen), two criteria are involved: reactor type and constructor. The procedure is as follows, beginning from the main RECAP menu (Fig. 3):

1. Enter option 5 to bring up Screen R020 (Select Units for Analysis, shown in Fig. 10).

2. Enter option 3 to bring up Screen R046 (Select Units by Reactor Type, shown in Fig. 15).

3. Enter a $\mathrm{Y}$ for BWRs and an $\mathbf{N}$ for pressurized water reactors (PWRs). Then press F10 to accept the input. Screen R020 (Fig. 10) reappears, updated to show that the number of units selected for case study has been reduced to 37 .

4. Enter 9 to bring up Screen R053 (Select Units by Constructor, shown in Fig. 21).

5. Enter a $Y$ for $B \& R$ and an $N$ for each of the other constructors. Then press F10 to accept the input. Screen R020 (Fig. 10) reappears, updated to show that the list now consists of only two reactors (Cooper and Oyster Creek), which are BWRs constructed by B\&R.

6. Press ESC to exit Screen R020 (Fig. 10) and return to the main RECAP menu.

These two criteria could also be selected in reverse order with the same final result.

There are two ways to restore units to the list for study after they have been eliminated. One is to press F5 from Screen R020 (Fig. 10), which restores all 112 units to the list. The other way is to move to Screen R048 (Select Units by Name, shown in Fig. 13) and restore units to the list individually. Screen-dependent restoration functions also appear on the bottom line of each unit selection screen. However, these screen-dependent functions only restore units to the configuration that existed when that screen was entered.

To exit the selection procedure, the user should press ESC from Screen R020 (Fig. 10). Pressing ESC returns the user to the main RECAP menu (Fig. 3). If option 6 from the main menu is then selected, the cost analyses performed will include only the units selected in option 5. As mentioned previously, if option 5 is not exercised before performing the cost analysis, all 112 reactors will be included. 


\subsection{OPTION 6: PERFORMING AN ENERGY REPLACEMENT COST ANALYSIS}

Once the desired set of reactors has jeen selected (as explained in Sec. 3.7), the user can proceed with the energy replacement cost analysis. Selecting option 6 from the main menu (Fig. 3) brings up a new pathway of options for defining the outage conditions (see the flow diagram for this portion of RECAP in Fig. 6).

The user-defined inputs include:

- Timing and duration of the shutdown (or derating) period,

- Changes in the default start-up dates for planned reactors or for units returning to service after an extended outage period,

- Changes in default capacity factors, and

- Selection of shutdown versus derating alternatives.

The steps involved in entering these inputs and completing the cost analysis are described below.

\subsubsection{Specifying the Shutdown or Derating Period}

The first screen brought up after option 6 is selected from the main RECAP menu is Screen R060 (Fig. 22), which requests the user to define the shutdown (or derating) period. The user is asked to specify the beginning year (between 1993 and 1996), the beginning day (from 1 to 365), and the length (in days, weeks, or years) of the shutdown period. The day numbers corresponding to each month are provided on the screen.

\subsubsection{Selecting General Conditions for the Analysis (start-up dates and capacity factors)}

After the shutdown timing and duration have been specified, Screen R055 (Fig. 23) appears, giving the user four options regarding unit start-up dates and capacity factors. The options are to (1) accept the default values used in the original study by VanKuiken et al. (1992) for both capacity factors and start-up dates, (2) make changes in unit start-up dates, (3) allow unit-specific or generic modifications to capacity factors, or (4) exercise both options 2 and 3.

Changes in start-up (or restart) dates may be important for planned reactors that are experiencing delays in start-up, or for units that have been on prolonged outages and are scheduled to renew operation. The default dates can be determined by returning to the main 


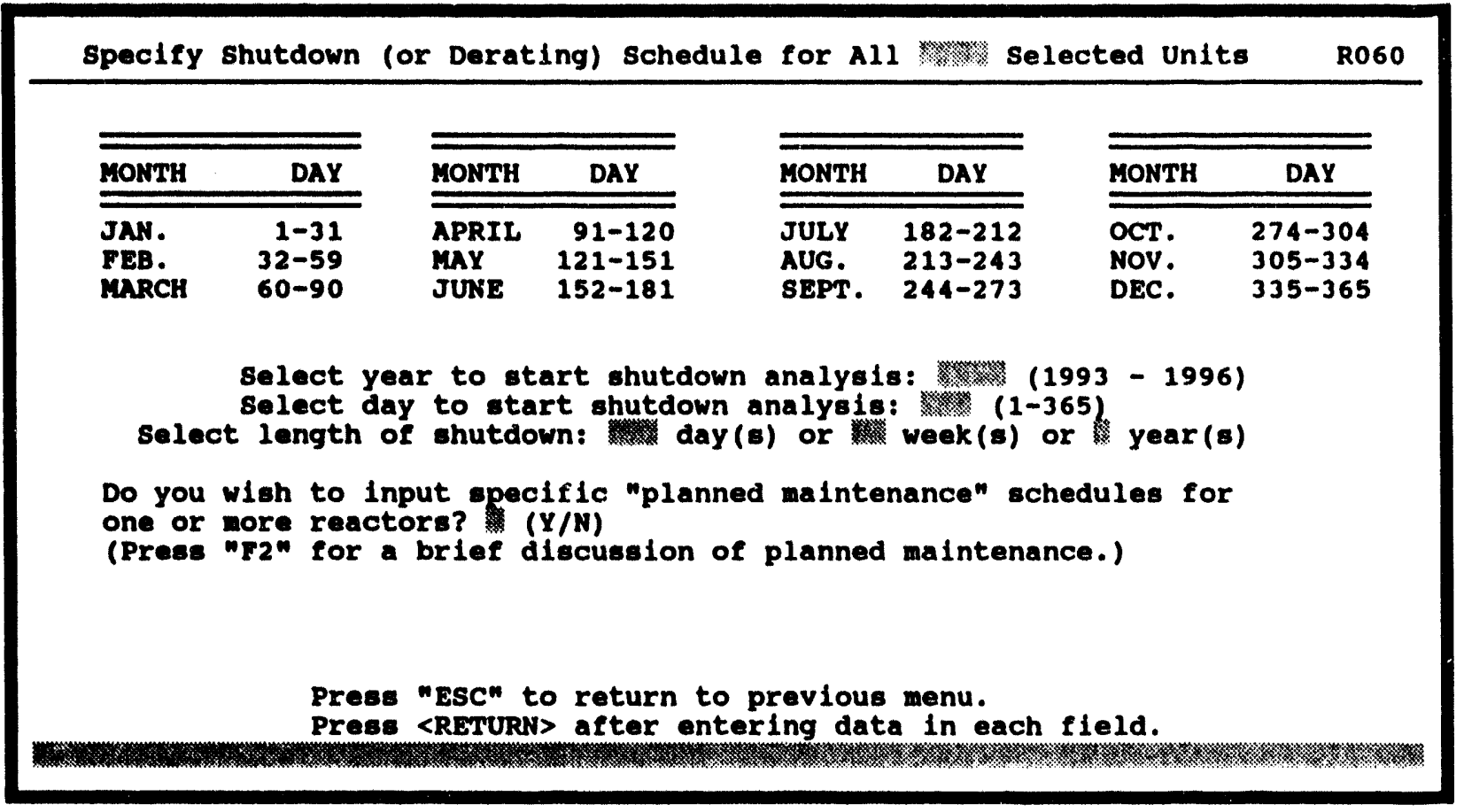

FGURE 22 Soreen RO60: Specify Shutdown Schedule for All Selected Units

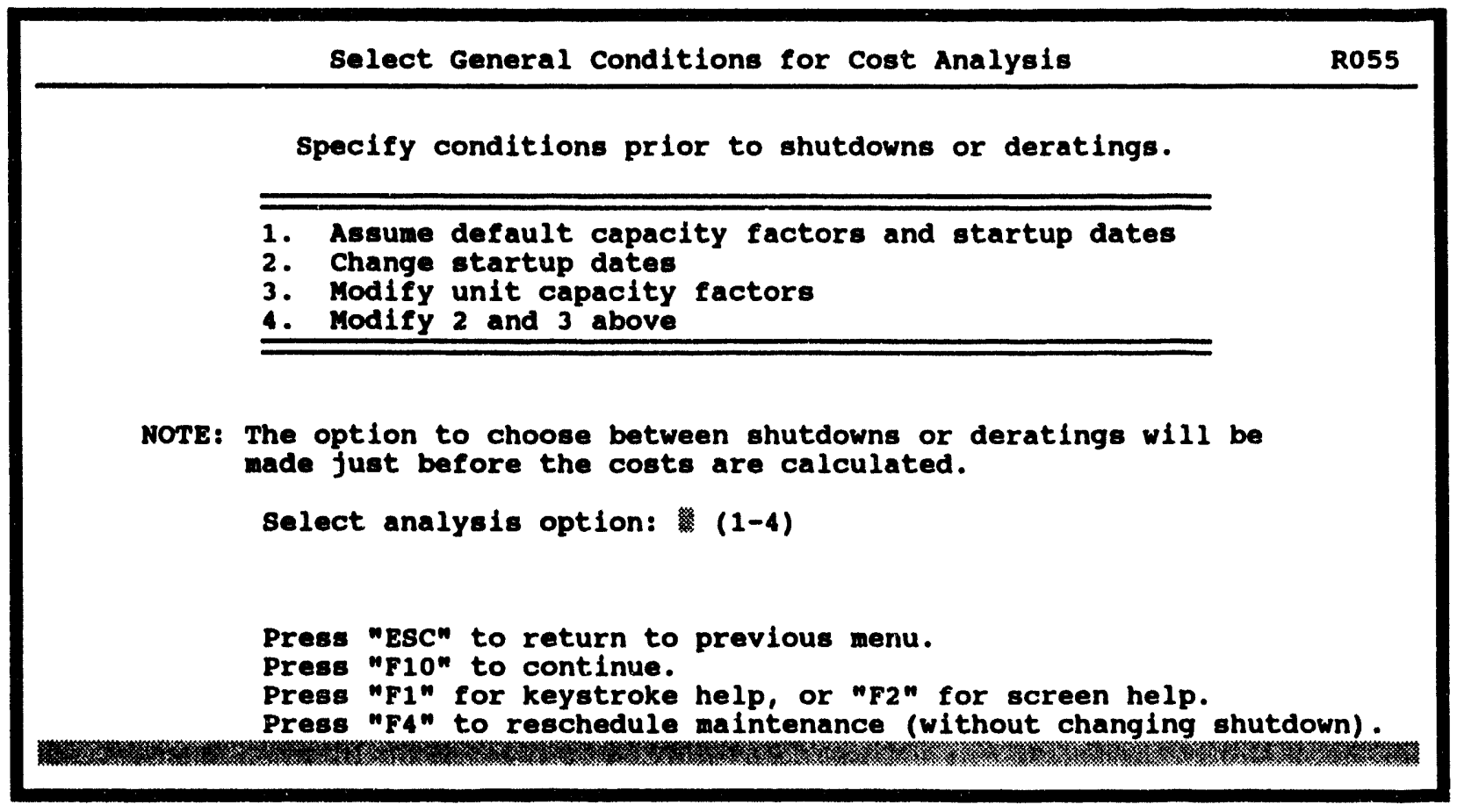

FGURI 23 Screen RO55: Select General Conditions for Cost Analysis 
RECAP menu, selecting option 5 (Select Units for Analysis), and pressing F7 to obtain a detailed review of the units that have been selected. The assumed start-up date for each unit appears by the field labeled "Actual Operation."

Selecting option 1 from Screen R055 (Fig. 23) instructs RECAP to adopt the default assumptions for start-up dates and capacity factors. The program proceeds directly to Screen R122, described in Sec. 3.8.3.

If option 2 is selected from Screen R055 (Fig. 23), indicating that changes will be made in start-up dates, two additional screens appear on which to make the changes. The first is Screen R110 (Fig. 24), which asks the user to designate which units will have changes in their start-up dates. The second is Screen R115 (Fig. 25), which requests new dates for each of the designatea units.

Unit capacity factors can be modified by the user to accommodate any unit-specific assumptions. When option 3 is selected from Screen R155 (Fig. 25), indicating that such modifications will be made, Screen R120 (Fig. 26) appears, listing the currently selected units and their average default capacity factors. An entry field is provided for new.capacity factors. The help screen explains that if a nonzero entry is made in the data field to apply to all units, this value overrides any unit-specific entries made on the screen. After all the entries have been made and the F10 key has been pressed, the program proceeds to Screen R122, described in Sec. 3.8.3.

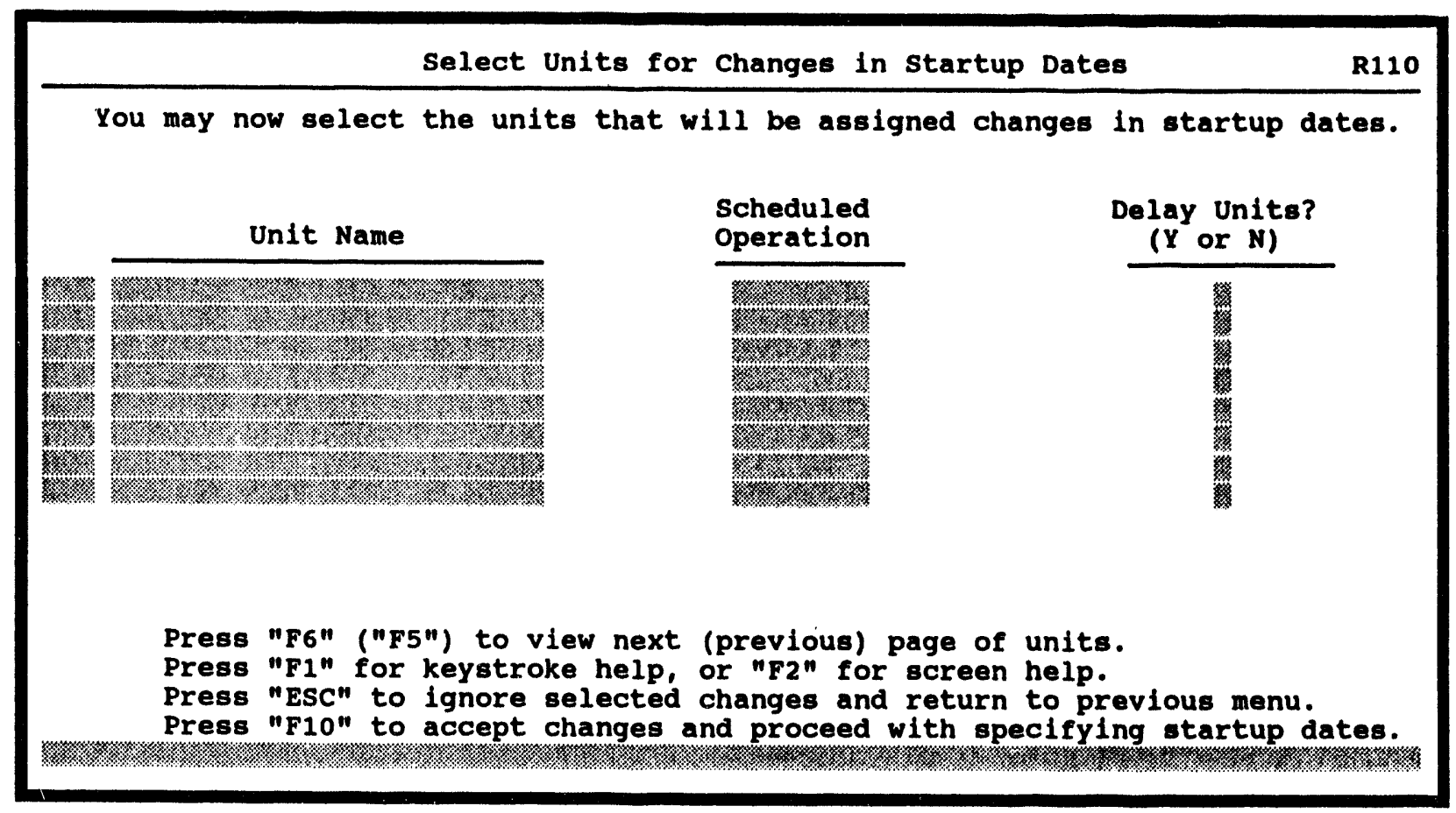

FIGURE 24 Screen R110: Select Units for Changes in Start-up Dates 


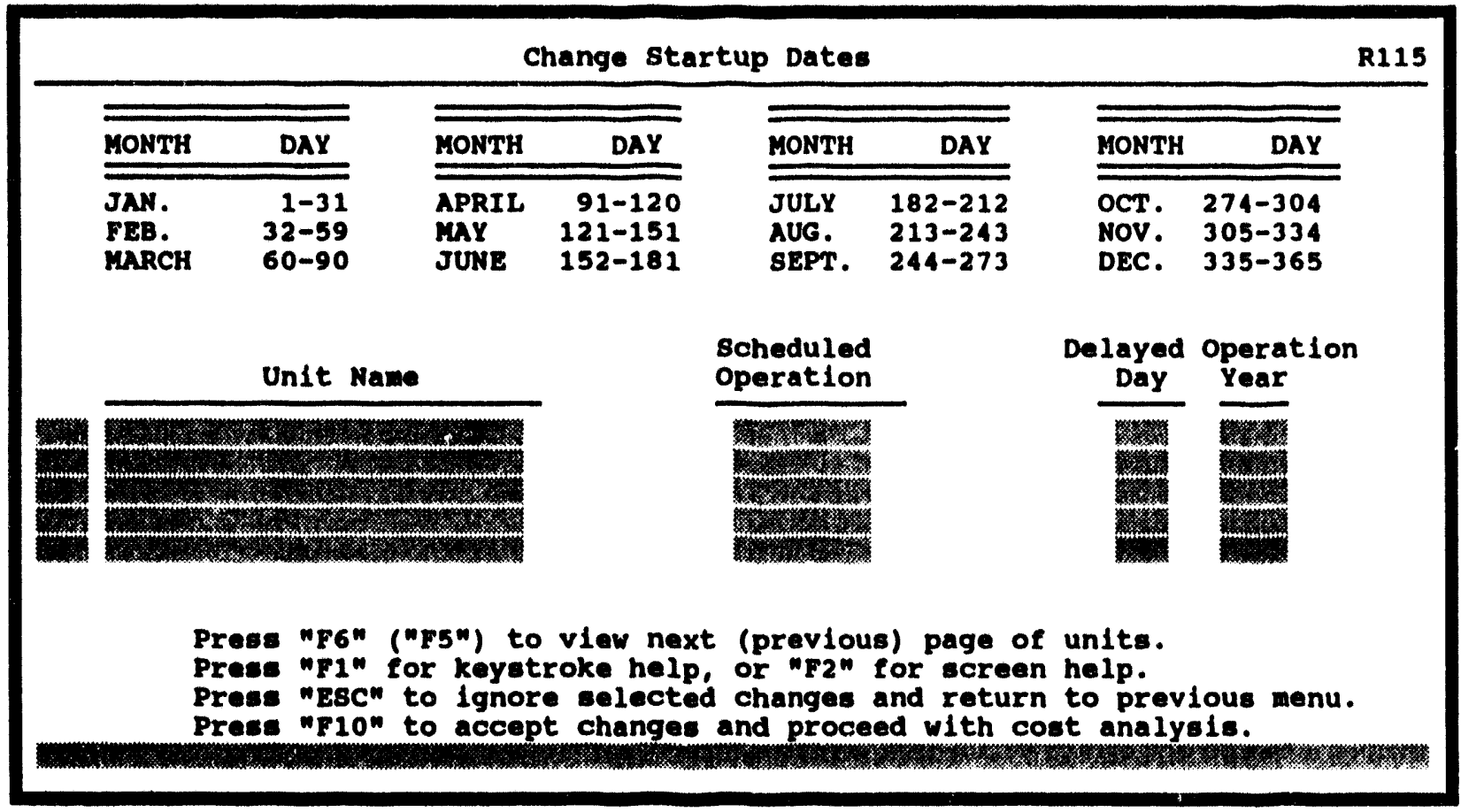

\section{FIGURE 25 Soreen R116: Change Start-up Dates}

Select New Capacity Factor

Enter new capacity factor for all units press "RETURN" to begin entering unit-specific capacity factors.

\section{Unit Name}

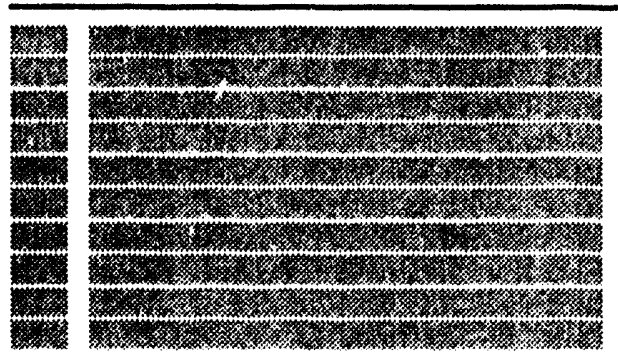

Average Capacity Factor

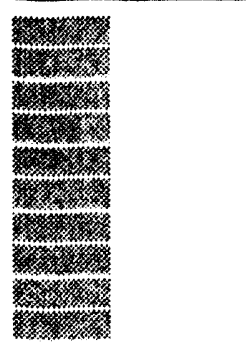

New Capacity Factor

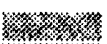

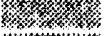

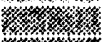

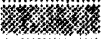

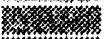

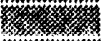

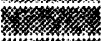

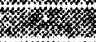

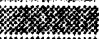

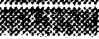

Press "F6" ("F5") to vlew next (previous) page of units.

Press "F1" for keystroke help, or "P2" for screen help.

Press "ESC" to Ignore selected changes and return to previous menu.

Press "F10" to accept changes and proceed with cost analysis.

当

\section{FGURE 26 Screen R120: Select New Capacity Factor}


The default capacity factors (typically 62-65\%) reflect average annual forced outage rates, routine scheduled maintenance and refueling outages, and other system-dependent limitations related to demands and operating constraints. The user may wish to modify the capacity factor assumptions if a better estimate can be made. Such cases may arise when evaluating short-duration outages for time periods when a reactor could normally be expected to operate at or near a capacity factor of $100 \%$.

Selecting option 4 from Screen R155 (Fig. 25) causes the program to sequence through the screens associated with both options 2 and 3, described above.

\subsubsection{Choosing between Shutdown and Derating Alternatives}

As a final input before RECAP performs the cost calculations, the user is prompted to choose either a full shutdown or a partial derating. At this point, the user has already (1) selected units for analysis (option 5 from the main menu) or assumed all units by default, (2) chosen to begin cost analysis (option 6 from the main menu), (3) specified the outage duration and timing (Screen R060, in Fig. 22), and (4) selected the general conditions for cost analysis (Screen R055, in Fig. 23, and associated screens).

The shutdown/derating choice is presented in Screen R122 (Fig. 27). Full shutdowns should be selected when reactors are to be removed from service during the outage period. Partial deratings should be specified when the selected group of units is expected to undergo a decrease in power output level, without total shutdown.

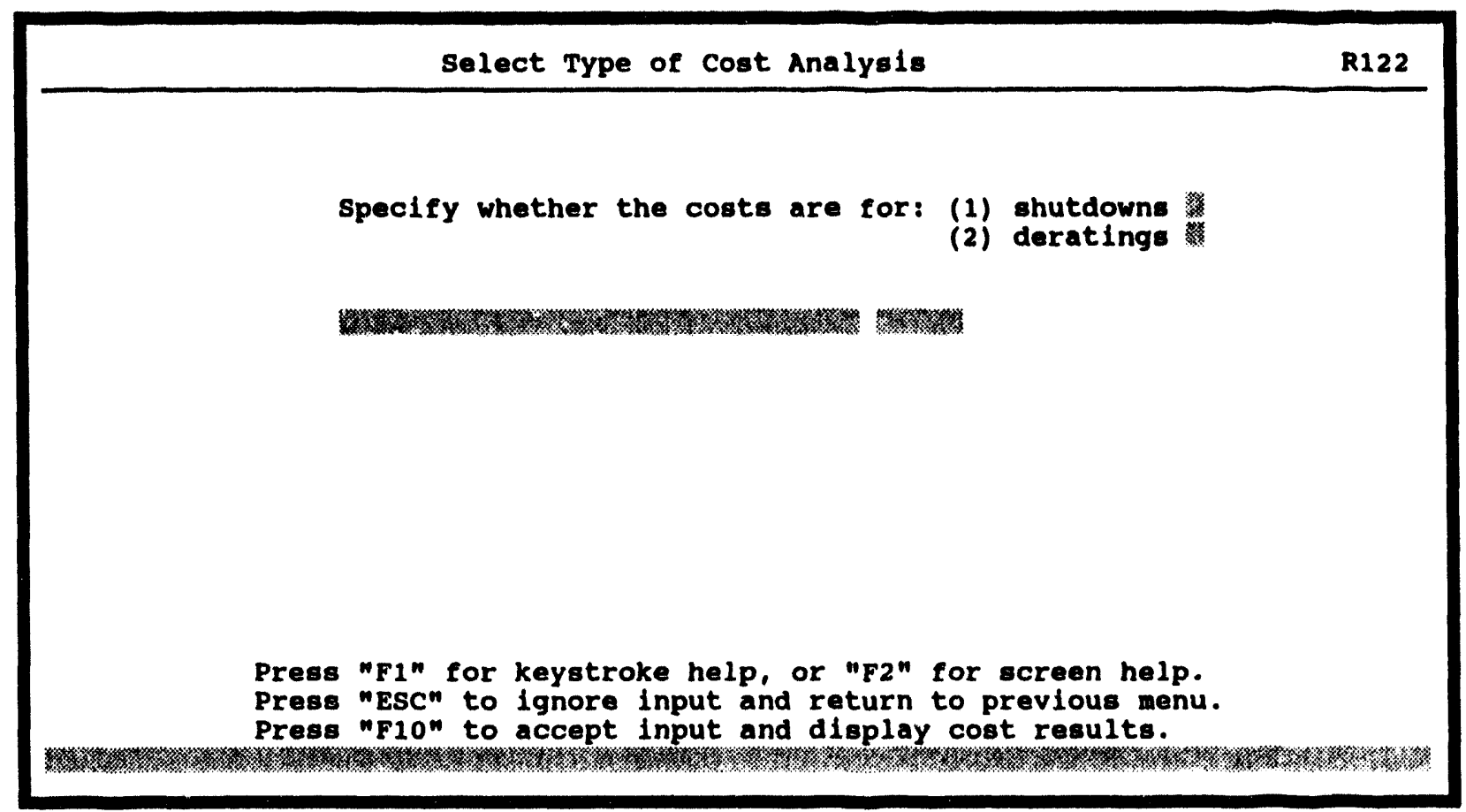

FIGURE 27 Screen R122: Select Type of Cost Analysis 
If the shutdown choice is selected, the program proceeds directly to the cost calculations. If the derating option is selected, an additional prompt is displayed on Screen R122 (Fig. 27) for the user to input the derating percentage. For example, a 5\% derating implies that a 1,000-MW reactor would be operating at $950 \mathrm{MW}$. A $100 \%$ derating would be equivalent to a full shutdown and would produce the same result as choosing a full shutdown on Screen R122 (Fig. 27).

Once the inputs from Screen R122 have been specified, the program pauses briefly as the calculations are made. A message appears at the bottom of the screen to notify the user first that the single-unit calculations are in progress and then that the multiple-shutdown adjustments are being applied. The length of the pause depends on the number of reactors included in the study and the length of the shutdown. On an IBM 386, the calculations for a 1-year shutdown for all 112 reactors takes approximately 0 seconds to complete.

\subsubsection{Viewing the Results}

When the calculations are completed, RECAP displays a multipage document that contains:

1. Two help screens explaining the output formats and viewing options,

2. A one-page summary for each unit included in the study (see the sample in Fig. 28),

3. A one-page summary of the results for all units (i.e., the summed singleunit costs, including adjustments for multiple-shutdown effects; see the sample in Fig. 29), and

4. A listing of all reactors included in the study.

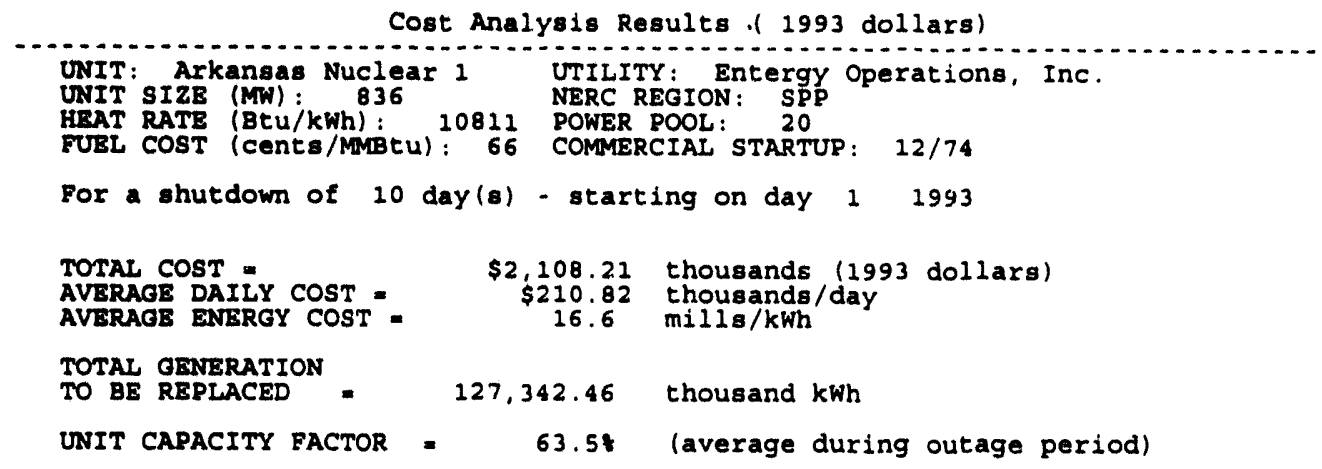

FGURE 28 Sample Coet Resultes Single Unit 


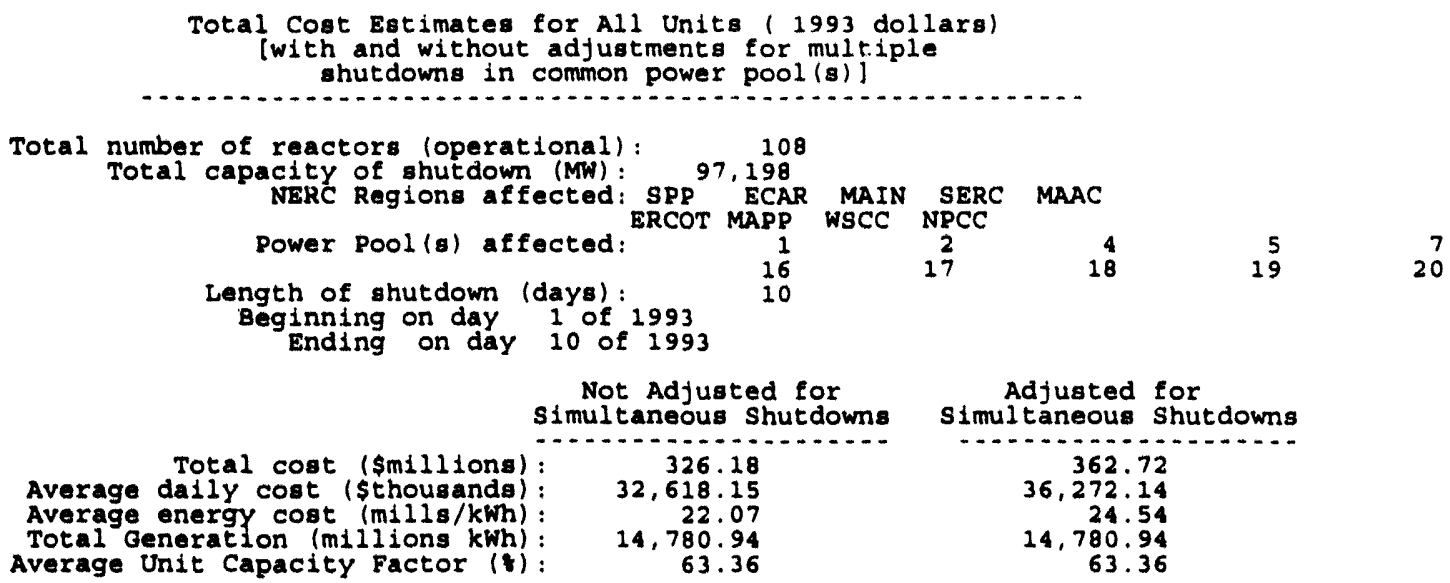

FIGURE 29 Sample Cost Resulte: All Units Combined

Several keyboard options are available to the user in this document review mode. The functions are similar to those described in Sec. 3.3 for reviewing the abstract. The PgUp and $\mathrm{PgDn}$ keys allow the user to scan the output tables one screen at a time. If the user enters a page number, and then presses the ENTER key, the screen display moves directly to the designated page. While the results are on-screen, they can be printed by pressing the asterisk key, followed by a 1 to print the current page only or a 2 to print the entire document. For studies involving a large number of reactors (greater than 66), the Ctrl-PgUp or Ctrl-PgDn key combinations can be used to scroll through the list of reactors one line at a time. The up and down arrows can be used to move up or down in the listing 20 lines at a time. 5

\subsubsection{Saving the Results}

The review of results can be exited by pressing the ESC key. Screen R125 (Fig. 30) then appears, asking the user if the results are to be saved for subsequent present-worth analyses. If the user's response is a $Y$, an additional message appears on the same screen requesting that an eight-character name be assigned to the result file. Both letters and numbers are valid characters in naming the file. After a valid file name is supplied and F10 is pressed, the program creates the new file with the cost results.

6 These features are not listed on the F1 help screen because they only apply to cases involving more than 66 reactors. In such cases, the unit listing is too long to be viewed in a single screen display. 
Note: Cost results must be saved if they are to be used later in a present worth analysis (Option 7 from main RECAP menu RO10).

After responding to the question below, RECAP will return to the

"Select General Conditions for Cost Analysis" menu R055 in case

additional sudies are to be run with the current set of selected

units. To proceed with present worth analysis, continue to press

"ESC" until the main RECAP menu (R010) appears.

There are user-defined files on disk; the maximum number allowed is 25.

Do you want to save the total cost results for this case study (Y/N)?

Press "F1" for keystroke help, or "F2" for screen help.

Press "ESC" to ignore input and continue.

Press "F10" to create data file and continue.

.

\section{FIGURE 30 Screen R125: Save Total Cost Estimates}

The user should be aware of two limits that affect file storage. One is that a maximum of 25 case-study files can be stored at one time. The other restriction is related to disk space requirements for each file. Each case study requires between 200 and 2,800 bytes of storage space, depending on the number of reactors included in a given study and the user-specified shutdown length. Therefore, disk space limitations will not typically be encountered as long as $70 \mathrm{kBytes}$ or more of hard disk space is available after the RECAP files are installed.

If either of the two file limitations is encountered when the user is trying to save a file, RECAP issues a warning message and ignores any requests to save additional files until one or more files have been deleted. The help screen for Screen R125 provides additional guidance for the user to respond to a warning message.

To preserve disk space, the user should only save the data files that will be used in subsequent present-worth analyses. A file deletion feature is included as part of the present-worth logic and is described in Sec. 3.10. It is important that all file deletions be made from within RECAP and not from the DOS environment. The RECAP logic contains a file catalog that records what file names are available for the present-worth calculations. Deleting files from outside RECAP interferes with this logic. 


\subsubsection{Continuing with Additional Cost Analyses}

After the user is given the option of saving the cost results, RECAP cycles back to Screen R055 (Fig. 23) to give the user an opportunity to conduct additional studies involving the same set of selected units and the same shutdown period. Screen R055 offers several choices for changing capacity factors or start-up dates.

At this point, the user may choose to input new selections and repeat the cost analysis from that step on. Alternatively, the user may press ESC to back up further in RECAP to Screen R060 (Fig. 22), which is the first screen brought up after option 6 (the cost analysis option) has been s.lected from the main RECAP menu (see Sec. 3.8.1). In this case, RECAP allows the user to redefine the shutdown period, while preserving the same set of reactors that was used for the last analysis. To change the set of reactors, the user should press the ESC key again to return to the main RECAP menu (Fig. 3) and then select option 5 (Select Units for Analysis).

The program cycle described above can be repeated for as many case studies as the user decides to investigate in a given session with RECAP. Once ESC has been pressed enough times to return to the main menu, option 6 may be selected again to continue with further cost analyses, or the user may proceed with other options, such as the present-worth calculations described in Sec. 3.9. The user may also choose to exit RECAP from the main menu (Fig. 3) by pressing ESC two more times.

\subsection{OPTION 7: PERFORMING A PRESENT-WORTH ANALYSIS}

The present-worth option is primarily useful for determining cost totals for sets of shutdown cases that cannot be examined in a single pass by using option 6 from the main menu. For example, the user may wish to determine the total costs for shutting down one group of reactors in the spring of 1993, another group of reactors in the winter of 1994, and still another group in the fall of 1995 . The present-worth option allows the user to determine the total costs, after first preparing three separate case studies using option 6 . In addition to summing the costs from separate case studies, option 7 also allows the user to redefine the reference year and to perform cost discounting calculations at user-specified discount rates. The flowchart in Fig. 7 illustrates the basic steps in conducting a present-worth review of previously saved case studies.

\subsubsection{Specifying the Inputs}

The present-worth analysis is initiated by selecting option 7 from the main RECAP menu (Fig. 3). The first screen brought up is Screen R011 (Fig. 31), which displays a menu of file names for the case studies that have been prepared and saved through option 6, described in Sec. 3.8. The user responds with a $\mathrm{Y}$ for the case studies to be included in the present-worth calculations. Screen R011 also contains the option for deleting old cost-result files that are stored on disk. This option is further discussed in Sec. 3.10. 


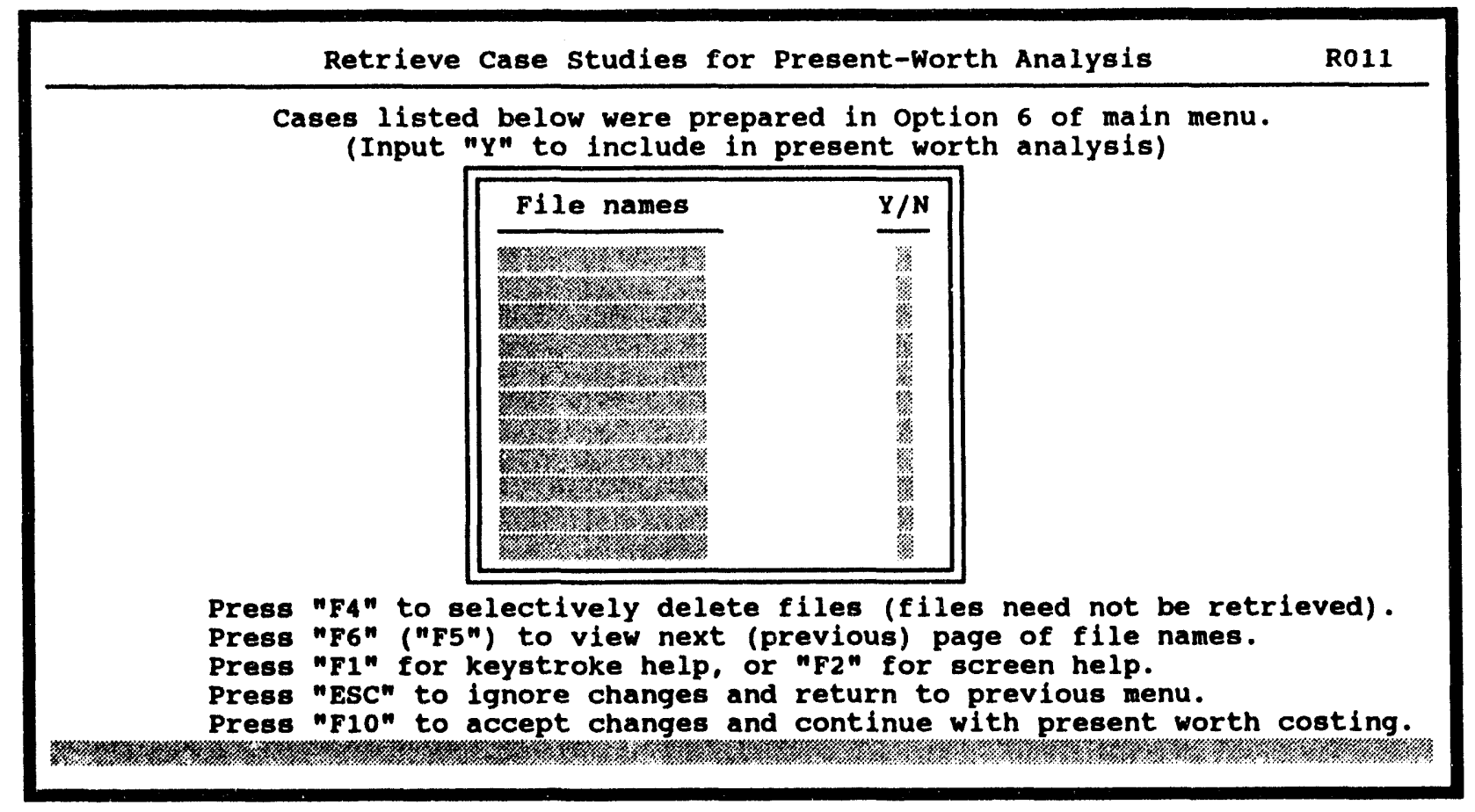

FIGURE 31 Screen R011: Retrieve Case Studies for Present-Worth Analysis

The program calculates a total present worth for all case studies selected from Screen R011. In this part of the program logic, no further adjustments are made for multiple outages in common power pools, and no tests are made for duplicate reactors or other potential inconsistencies. Therefore, the user should take care in structuring the case definitions for the cost analyses done in option 6. A disc ssion of special strategies for overlapping shutdown periods is contained in Sec. 3.11.

After the case studies are selected, Screen R013 (Fig. 32) appears with four input fields to define the costing parameters. The first parameter is the reference year to be used for reporting cost totals. The second is the reference-year cost multiplier. The default cost multiplier uses 1993 as a base year and assumes that GNP price deflators apply to the other years between 1989 and 1993 . The user may override the default assumptions by specifying any reference-year cost multiplier.

The last two inputs requested are a target year for discounting and a real annual discount rate. For most studies, the NRC assumes a $7 \%$ real annual discount rate. For sensitivity tests, a rate of 5\% is sometimes used. However, RECAP allows the user to select any real annual discount for the present-value calculations. The discounting calculations are based on the length of time between the midpoint of each shutdown period and the middle of the target year. For improved precision in cases involving multiple-year shutdowns, the user is urged to prepare and save separate cases for each year of the study. 


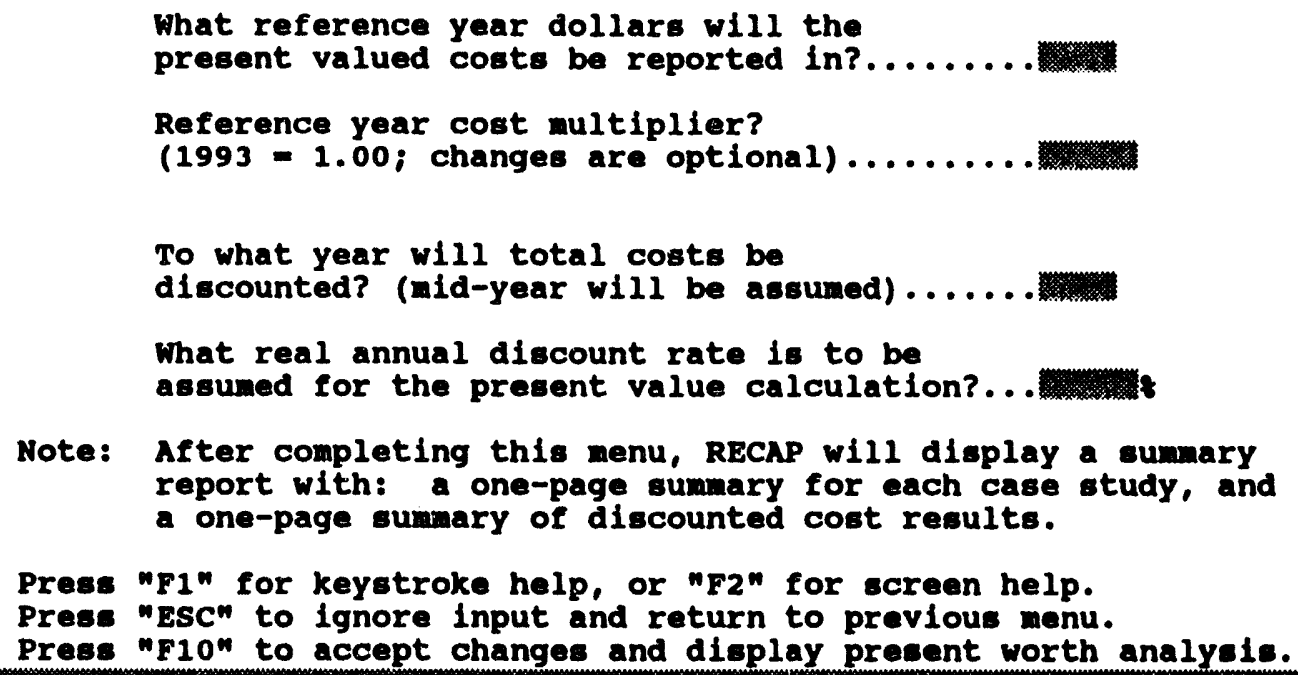

FIGURE 32 Screen R013: Input Present-Worth Costing Parameters

\subsubsection{Viewing the Results}

After the inputs on Screen R013 are completed and F10 is pressed, RECAP performs the necessary calculations and displays the final results. The results can be reviewed on-screen and printed by using the same keyboard commands as used with the cost analysis results (see Sec. 3.8.4). For example, the Ctrl-PgUp and Ctrl-PgDn key combinations, as well as the up and down arrows, can be used for scrolling through results that are too long to be displayed on a single screen.

The output screens are organized into three sections. The first is one page of descriptive text that describes the output formats and viewing options. The second consists of a one-page summary table for each case study included in the present-worth analysis. A sample summary page is shown in Fig. 33. The one-page summaries include identifying information such as the file name, length and timing of the shutdown, number of units in the case study, and the cost and generation totals. The adjusted costs displayed reflect the multiple-shutdown adjustments for that case study from option 6 (no further adjustments are made during the present-worth calculations).

The third and final portion of the results is a one-page table that displays the combined costs and generation totals for all of the cases together. Figure 34 illustrates the format of this summary table. At the top of the screen, the user-defined present-worth costing parameters are repeated to identify the key assumptions of the case study. These are followed by adjusted and unadjusted cost estimates and the generation totals. 
Brief Review of Data Saved in: TRIALALL.DAT

(See Last Page for Present Worth Analysis)

Start Day......................... 1

Start Year........................... 1993

Length of Shutdown (days).............. 1095

Number of Units..................... 112

Undiscounted Total Costs (Unadjusted).... 36,439.81 (1993 Smillions)

Undiscounted Total Costs (Adjusted)*..... 40,591.10 (1993 smillions)

Undiscounted Avg. Energy Cost (Unadjusted) 21.95 (mills/kWh)

Undiscounted Avg. Energy Cost (Adjusted)*. 24.45 (mills/kWh)

Total Generation (Millions kWh).........1,660,023.25

- Adjusted for multiple shutdowns

List of Unit Names

\begin{tabular}{|c|c|c|}
\hline $\begin{array}{l}\text { Arkansas Nuclear } 1 \\
\text { Beaver Valley } 2 \\
\text { Braidwood } 2 \\
\text { Browns Ferry } 3 \\
\text { Byron } 1 \\
\text { Calvert Cliffs } 1 \\
\text { Catawba } 2 \\
\text { Comanche Peak } 2 \\
\text { Cooper } \\
\text { Diablo Canyon } 1 \\
\text { Dresden } 3 \\
\text { farley } 2 \\
\text { Fort Calhoun } \\
\text { Haddan Neck } \\
\text { Hatch } 2 \\
\text { Indian Point } 3 \\
\text { La Salle } 2 \\
\text { Maine Yankee } \\
\text { Millstone } 1 \\
\text { Monticello } \\
\text { North Anna } 1 \\
\text { Oconee } 2 \\
\text { Palisades } \\
\text { Palo Verde } 3 \\
\text { Perry } 1 \\
\text { Point Beach } 2 \\
\text { Ouad-Cities } 1 \\
\text { Robinson } 2 \\
\text { San Onofre } 1 \\
\text { Seabrook } 1 \\
\text { South Texas } 1 \\
\text { St. Lucie } 2 \\
\text { Surry } 2 \\
\text { Three Mile Island } 1 \\
\text { Turkey Point } 4 \\
\text { Vogtle } 2 \\
\text { Watts Bar } 1 \\
\text { Zion } 2\end{array}$ & $\begin{array}{l}\text { Arkansas Nuclear } 2 \\
\text { Big Rock Point } \\
\text { Browns Ferry } 1 \\
\text { Brunswick } 1 \\
\text { Byron } 2 \\
\text { Calvert Cliffs } 2 \\
\text { Clinton } \\
\text { Cook } 1 \\
\text { Crystal River } 3 \\
\text { Diablo Canyon } 2 \\
\text { Duane Arnold } \\
\text { Fermi } 2 \\
\text { Ginna } \\
\text { Harris } 1 \\
\text { Hope Creek } 1 \\
\text { Kewaunee } 1 \\
\text { Limerick } 1 \\
\text { McGuire } 1 \\
\text { Millstone } 2 \\
\text { Nine Mile Point } 1 \\
\text { North Anna } 2 \\
\text { Oconee } 3 \\
\text { Palo Verde } 1 \\
\text { Peach Botton } 2 \\
\text { Pilgrim } 1 \\
\text { Prairie Island } 1 \\
\text { Ouad-Cities } 2 \\
\text { Salem } 1 \\
\text { San Onofre } 2 \\
\text { Sequoyah } 1 \\
\text { South Texas } 2 \\
\text { Sumer } \\
\text { Susquehanna } 1 \\
\text { Trojan } \\
\text { Vermont Yankee } \\
\text { Washington Nuclear } 2 \\
\text { Wolf Creek } 1 \\
\text { Holf }\end{array}$ & $\begin{array}{l}\text { Beaver Valley } 1 \\
\text { Braidwood } 1 \\
\text { Browns Ferry } 2 \\
\text { Brunswick } 2 \\
\text { Callaway } \\
\text { Catawba } 1 \\
\text { Comanche Peak } 1 \\
\text { Cook } 2 \\
\text { Davis-Besse } \\
\text { Oresden } 2 \\
\text { Farley } 1 \\
\text { Fitzpatrick } \\
\text { Grand Gulf } 1 \\
\text { Hatch } 1 \\
\text { Indian Point } 2 \\
\text { La Salle } 1 \\
\text { Limerick } 2 \\
\text { McGuire } 2 \\
\text { Millstone } 3 \\
\text { Nine Mile Point } 2 \\
\text { Oconee } 1 \\
\text { Oyster Creek } \\
\text { Palo Verde } 2 \\
\text { Peach Bottom } 3 \\
\text { Point Beach } 1 \\
\text { Prairie Island } 2 \\
\text { River Bend } 1 \\
\text { Salem } 2 \\
\text { San Onofre } 3 \\
\text { Sequoyah } 2 \\
\text { St. Lucie } 1 \\
\text { Surry } 1 \\
\text { Susquehanna } 2 \\
\text { Turkey Point } 3 \\
\text { Vogtle } 1 \\
\text { Waterford } 3 \\
\text { 2ion } 1 \\
\text { Ton }\end{array}$ \\
\hline
\end{tabular}

FIGURE 33 Sample Present-Worth Results: Single Case Study 


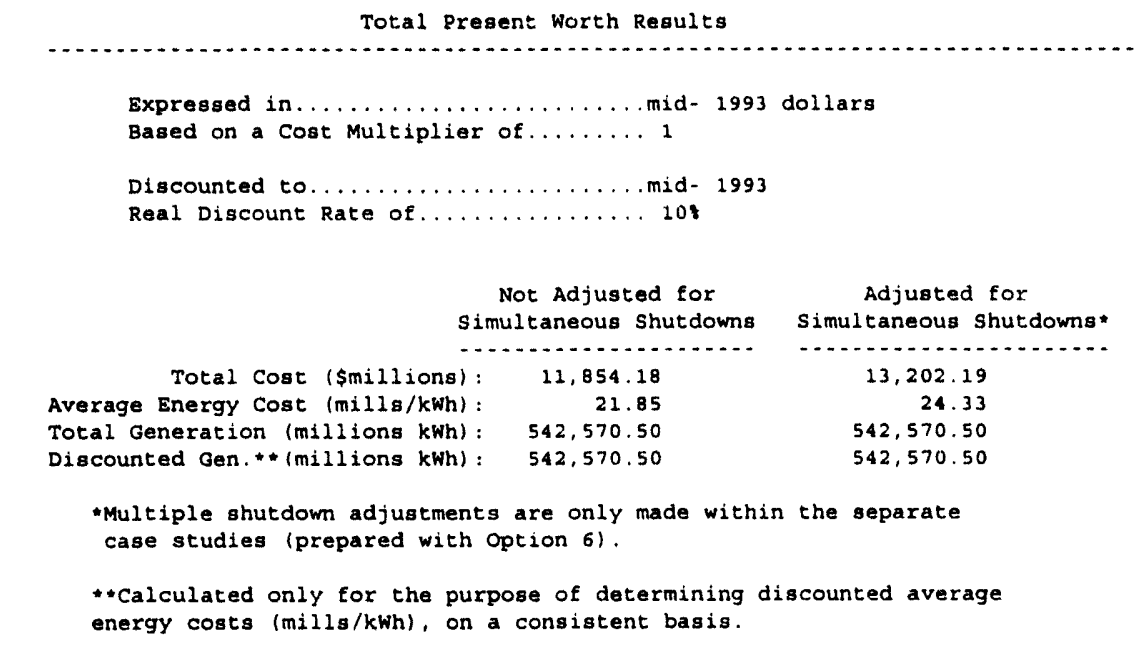

\section{FIGURE 34 Sample Present-Worth Results: All Case Studies Combined}

\subsubsection{Continuing with Additional Present-Worth Analyses}

To exit the present-worth results, the user presses ESC, which returns the user to Screen R013 (Fig. 32). This screen enables the user to define the costing parameters. At this point, the user can choose to input new parameters and perform additional present-worth analyses by using the same set of case studies as before. Alternatively, the user can press ESC again to return to Screen R011 (Fig. 31), where a new set of case studies can be selected for a present-worth evaluation. Pressing ESC once more returns the user to the main RECAP menu (Fig. 3), where any of the original seven options may be selected.

\subsection{DELETING FILES}

Screen R011 (Fig. 31) is the correct point at which old files can be deleted if they are of no further use. As explained in Sec. 3.8.5, it is important that all file deletions be made from within RECAP and not from the DOS environment. From Screen R011, the user should press F4 to bring up Screen R012 (Fig. 35), which prompts for the file names to be deleted. If an error is made while designating $\mathrm{Y}$ or $\mathrm{N}$ for each file name, the user may either (1) back up with the up arrow to make a correction or (2) press ESC to cancel the request to delete files and return to the previous menu (Screen R011, Fig. 31). Pressing F10 deletes the designated files and returns the user to Screen R011.

If the user inadvertently deletes a file, or set of files, from DOS, it is necessary to recreate new files, with the same names as the deleted files, by using option 6 from the main menu (Screen R010, shown in Fig. 3). These new files can then be either deleted from Screen R012 (Fig. 35), as described above, or kept for later use in the present-worth analyses described in Sec. 3.9. 


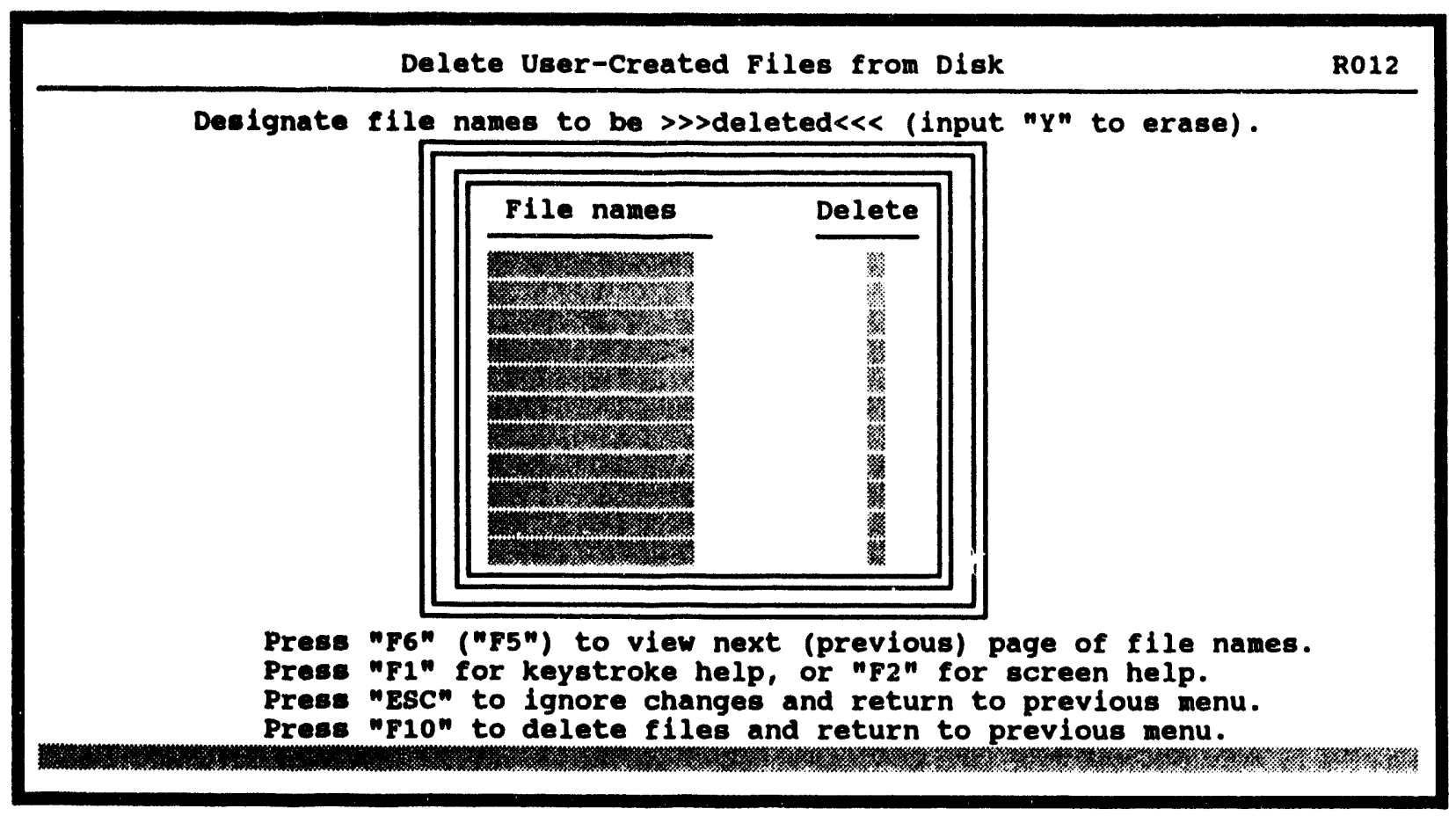

FGURE 36 sereen R012: Delete User-Created Files from Disk

\subsection{ANALYSIS STRATEGIES FOR OVERLAPPING SHUTDOWNS}

Situations may arise in which the user wants to examine different shutdown periods that overlap for more than one reactor in a given power pool. This special combination makes it more difficult to account for the multiple-shutdown impacts on outage costs. Option 6 from the main menu (Fig. 3) treats the effects of multiple shutdowns on costs, but it requires that the shutdown period be the same for all reactors in a given case study. Option 7 from the main menu (Fig. 3) allows the user to sum and discount costs from alternative shutdown periods, but it does not treat multiple-shutdown impacts beyond those treated in option 6.

To bypass this difficulty, the user may need to construct a special-case definition by using the start-up date option included in option 6 . The following example demonstrates this strategy.

Assume that two reactors, A and B, are in the same power pool, and that replacement energy costs are to be determined for reactor A to be shut down for July and August of 1993, and for reactor B to be shut down for August and September of the same year. Then, preparing two separate case studies for each reactor using option 6 and totaling the results using option 7 misses the fact that there should be a multiple-shutdown adjustment for the overlapping portion of the outages.

In this situation, the user is advised to perform one two-month outage case study (July through August 1993) and a separate one-month case study for September. The option 
to alter the assumed start-up dates can be used to simulate the appropriate outage time periods. For the two-month case, the start-up date for reactor B could be changed to day 213 of 1993 (first day of August), so no outage costs would accrue for reactor B during the month of July. This would allow RECAP to recognize the simultaneous outage for August. The second case would only be run for reactor $B$ to determine the single-reactor outage costs for September. After saving the results, option 7 could be used to add and discount the results.

Alternatively, the user could perform three separate case studies by using option 6 and then sum the results by using option 7. The first study in option 6 would be a one-month shutdown for reactor $A$ in July. The second study would be a one-month outage for both reactors in August (which would treat the simultaneous-outage effects). The third case study would be a one-month outage for reactor B in September. After the results for all three case studies are saved (in option 6), option 7 could then be used to add and discount the costs.

\subsection{HXITING RECAP}

To exit RECAP, the user should press ESC repeatedly to move backward from the current location in the program structure (diagrammed in Figs. 4-7). The number of repetitions required to fully exit the program depends on the user's location. From the main RECAP menu (see Screen R010 in Fig. 3), the ESC key must be pressed only twice. From Screen R125, which is farther along a logical pathway (see Fig. 5), the ESC key must be pressed five times. The exact number of times that ESC must be pressed is not critical, as long as it is pressed enough times to back all of the way out of the program.

Therefore, for the quickest exit, the user can simply press the ESC key rapidly for six to eight times without waiting to see which screen appears after each entry. However, the user should be certain that he or she is finished with RECAP because, upon exiting, the program returns the user to the DOS environment, and restarting the program involves a time delay associated with data initialization. 


\section{REFERENCES}

VanKuiken, J.C., et al., 1992, Replacement Energy Costs for Nuclear Electricity-Generating Units in the United States: 1992-1996, NUREG/CR-4012, Vol. 3, U.S. Nuclear Regulatory Commission, ANL/AA-30, Vol. 3, Argonne National Laboratory.

DOE, 1985, Cost and Quality of Fuels for Electric Plants, 1985, DOE/EIA-0191 (85), U.S. Department of Energy, Washington, D.C.

DOE, 1992, Cost and Quality of Fuels for Electric Plants, 1986, DOE/EIA-0191 (86), U.S. Department of Energy, Washington, D.C.

DOE, 1987, Cost and Quality of Fuels for Electric Plants, 1987, DOE/EJA-0191 (87), U.S. Department of Energy, Washington, D.C.

DOE, 1988, Cost and Quality of Fuels for Electric Plants, 1988, DOE/EIA-0191 (88), U.S. Department of Energy, Washington, D.C.

DOE, 1989, Cost and Quality of Fuels for Electric Plants, 1989, DOE/EIA-0191 (89), U.S. Department of Energy, Washington, D.C.

DOE, 1990, Cost and Quality of Fuels for Electric Plants, 1990, DOE/EIA-0191 (90), U.S. Department of Energy, Washington, D.C.

DOE, 1991, Cost and Quality of Fuels for Electric Plants, 1991, DOE/EIA-0191 (91), U.S. Department of Energy, Washington, D.C. 


\section{APPENDL: \\ DLAGRAM OF SCREENS BY OPERATIONAL SEQUENCE}

This appendix presents a quick reference chart (Fig. A.1), for the user's convenience, of all of the RECAP input screens as they occur in the program logic. The screens are identified by their reference number only. Full descriptions can be found in the main text of this report. Some program pathways lead to display screens rather than input screens, such as option 1 from Screen R010 (the main menu), which leads to a text display of the program abstract. These pathways are also shown.

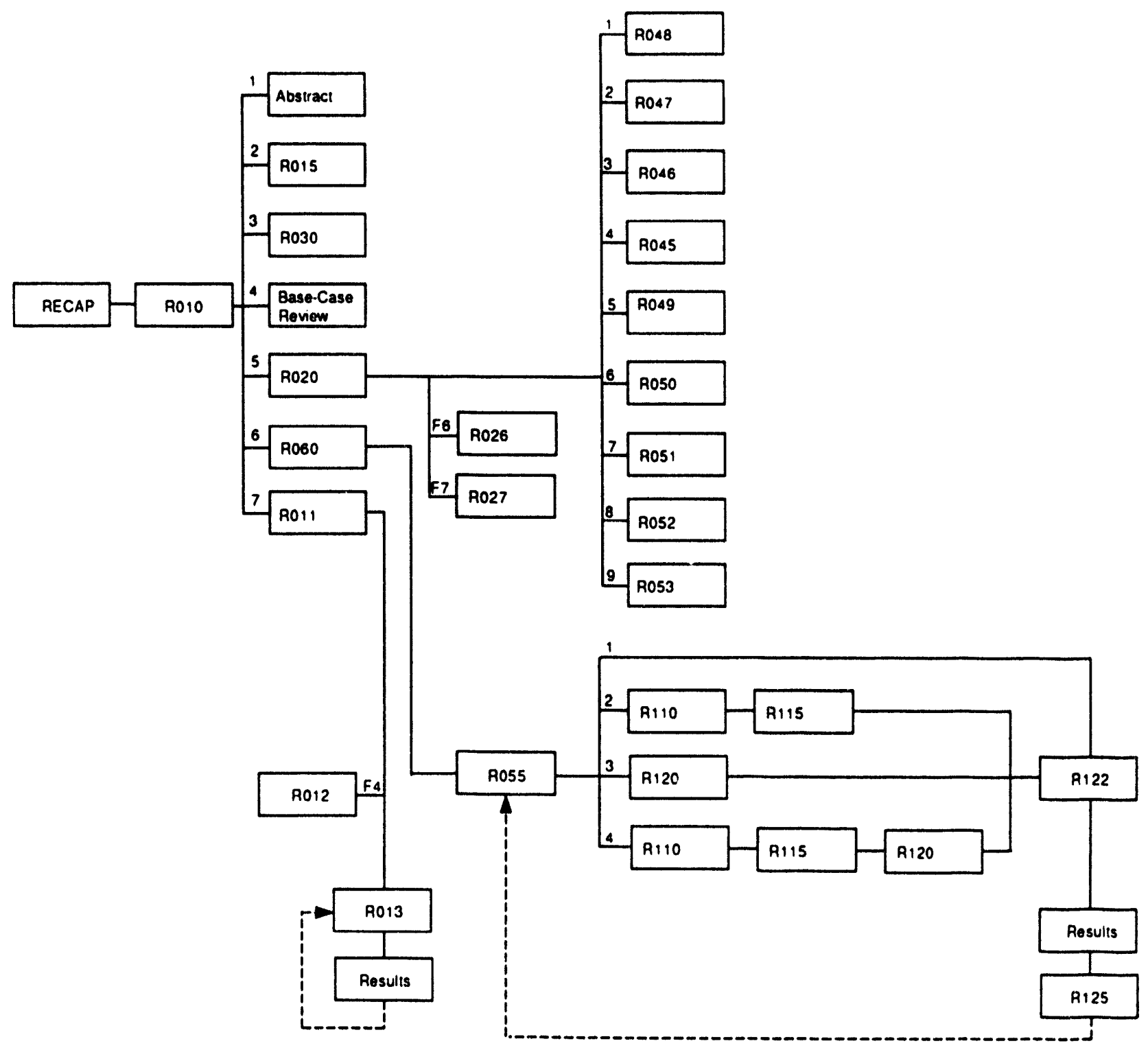

FIGURE A1 Quick User's Chart of RECAP Input Soreens 


\section{DISTRIBUTION FOR NUREG/CR-6344 (ANL/EES-TM-364)}

Internal
ANL Technical Publications Services
N. Clodi (5)
M. Clemmons
J. VanKuiken (43)

\section{External}

U.S. Nuclear Regulatory Commission for distribution per 9C, 9D, GF Manager, U.S. Department of Energy Chicago Field Office ANL-E Libraries

ANL-W Library

S. Feld, U.S. Nuclear Regulatory Commission 

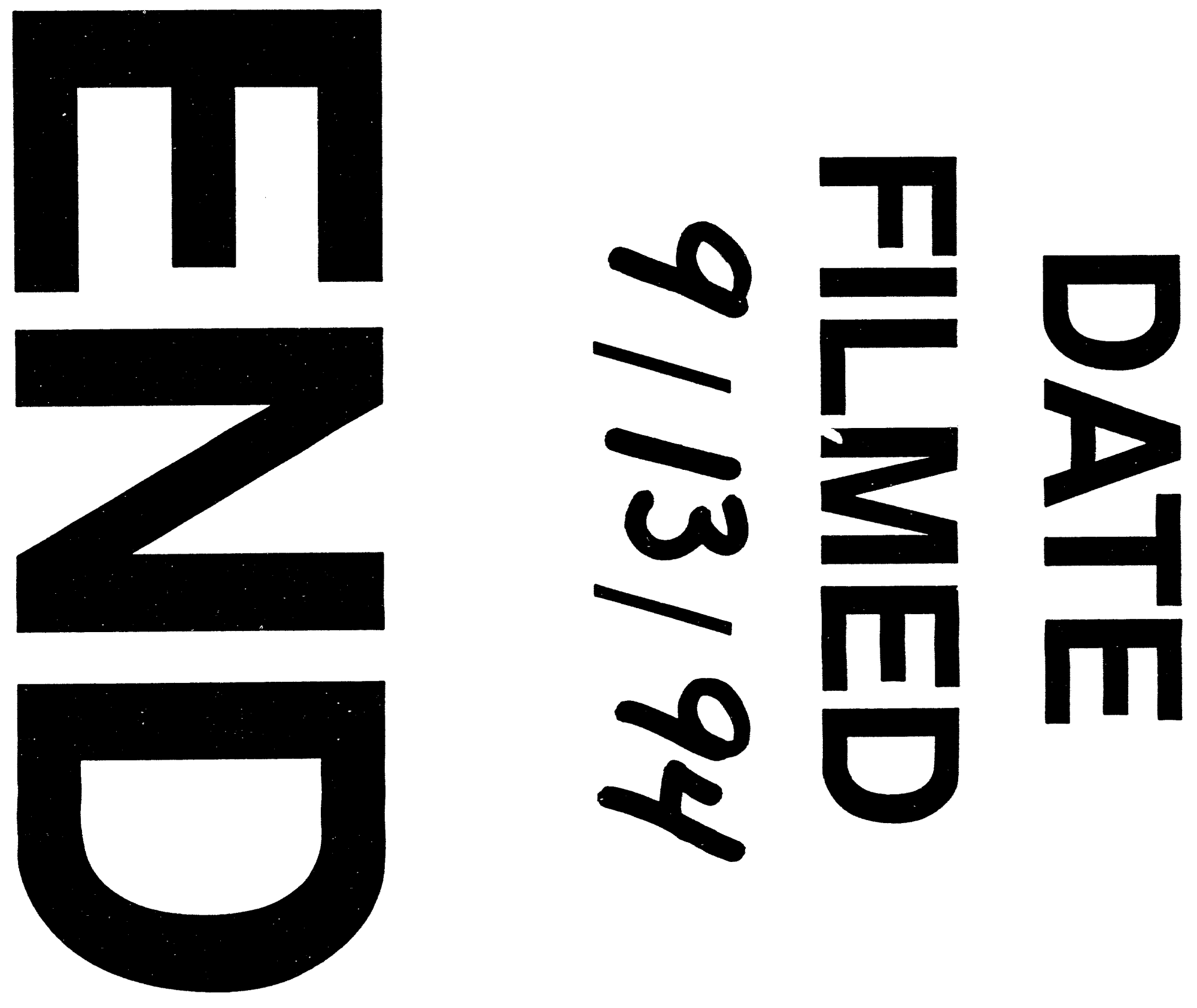
